SAND90-2091

Unlimited Release

September 1990

\title{
THE INCLUSION OF WALL LOSS IN ELECTROMAGNETIC FINITE-DIFFERENCE TIME-DOMAIN THIN-SLOT ALGORITHMS
}

\author{
Douglas J. Riley and C. David Turner \\ Radiation and Electromagnetic Analysis Division \\ Sandia National Laboratories \\ Albuquerque, NM 87185
}

\begin{abstract}
Sub-gridding techniques enable finite-difference time-domain (FDTD) electromagnetic codes to model apertures that are much narrower than the spatial resolution of the FDTD mesh. Previous thin-slot method have assumed that the slot walls are perfectly conducting. As the slot depth-to-width ratio becomes large, interior wall losses for realistic materials can significantly affect the coupling through the slot, and therefore these loss effects should not be neglected. This paper presents two methods for incorporating loss for walls with good, but not perfect conductivity, into the FDTD calculations. The first method modifies an FDTD equation internal to the slot to include a surface-impedance contribution. This method is appropriate for the usual FDTD thin-slot formalisms. The second method includes the losses into a "half-space" integral equation that can be used by the recently introduced Hybrid Thin-Slot Algorithm. Results based on the two methods are compared for a variety of slot parameters and wall conductivities.
\end{abstract}




\section{LIST OF CONTENTS}

$\underline{\text { Section }}$

Page

1 INTRODUCTION

2 ANALYSIS

A. Direct Inclusion into FDTD Equations

B. Hybrid Thin-Slot Algorithm with Wall

Loss and Lossy Gaskets

3 NUMERICAL RESULTS AND DISCUSSION

22

4 CONCLUDING REMARKS

34

REFERENCES

34

APPENDIX A: Thin-Slot Equations for H-Wall

Implementation

35

APPENDIX B: Evaluation of Retarded-Time Integral for $\mathrm{a}<<\mathrm{y}_{0}<<\Delta$ 


\section{LIST. OF FIGURES}

Figure

Page

1. Geometry of a long slot of depth d and width w showing interior FDTD fields. The slot is assumed to be of length $\mathrm{L}$ in the $\mathrm{x}$ direction and composed of many similar FDTD cells. Note that tangential $\mathrm{H}$-fields define the entering and exiting planes of the slot (H-wall).

2 Contour used to include wall loss into the FDTD equation for advancing $\mathrm{H}_{y_{\mathrm{a}}}$. This contour is unique to the interior of the slot. For simplicity, the depth is assumed to be one FDTD cell.

FDTD mesh for using the HTSA. Walls defined on tangential E-fields (E-wall). Slot is shorted when HTSA is used. A uniform FDTD cell is assumed with free space in both regions.

Test geometry for comparing the two loss methods. Wall thicknesses were $1 \mathrm{~cm}$. The cavity depth $\because$ as $5.5 \mathrm{~cm}$ when the front face was modeled using the H-wall approach and tho cell size was $1 \mathrm{~cm}$. Cavity depth was $5 \mathrm{~cm}$ for the HTSA. Slot centered on front face for HTSA solution. Wire loaded with $50 \mathrm{ohms}$ at each end. Only the wall regions inside the slot were assumed to be lossy.

Slot electric field $5 \mathrm{~mm}$ off slot midpoint showing loss effects as the wall conductivity decreases. Slot width: $0.1 \mathrm{~mm}$. Results based on HTSA formulation.

Same as Fig. 5 , but with a slot width of $1 \mathrm{~mm}$.

Wire current at wire's midpoint as the slot's wall conductivity decreases. Wire loaded with $50 \mathrm{ohms}$ at its ends. Slot width: $0.1 \mathrm{~mm}$. Wire length: $5 \mathrm{~cm}$. Results based on HTSA formulation.

Same as Fig. 7, but with a slot width of $1 \mathrm{~mm}$.

Slot electric field at a position $5 \mathrm{~mm}$ from slot's midpoint.

Comparison of the H-vall TSF (with loss) and HTSA for a $0.1-\mathrm{mm}$ wide slot and wall conductivity approximately corresponding to aluminum. One-cm FDTD cell size. H-wall result at slot's dopth midpoint.

10 Slot electric field at a position $5 \mathrm{~mm}$ from slot's midpoint.

Comparison of the H-wall TSF (with loss) and HTSA for a $0.1-\mathrm{mm}$ wide slot with large wall losses. One-cm FDTD cell size. H-wall TSF result at slot's depth midpoint. 
11 Same as Fig. 10, but with an FDTD cell size of $1 / 3 \mathrm{~cm}$. H-wall TSF result based on $\mathrm{E}$-field closest to the front face of the box.

12

Slot electric field 5-mm off slot's midpoint. Dielectric gasket with $\epsilon_{\mathrm{g}}=2 \epsilon_{\mathrm{o}}$ placed in slot. Wall conductivity: $3.5 \mathrm{e} 5 \mathrm{~S} / \mathrm{m}$. Slot width $0.1 \mathrm{~mm}$. Comparison with and without gasket. HTSA formulation.

A1 Contours used to generate an $\mathrm{H}-$ wall TSF. 


\section{INTRODUCTION}

The modeling of electromagnetic coupling into enclosures often requires the resolution of very narrow apertures. Adequate spatial resolution is often not possible in practical finite-difference time-domain (FDTD) codes, and therefore alternative "sub-gridding" techniques have been investigated $[1,2,3]$. These methods have inherently assumed that the walls bounding the aperture are perfect electric conductors; however, as the slot's depth to width ratio becomes large $(>>1)$ the interior wall losses in realistic materials that are good, but, of course, not perfect, conductors can significantly alter the penetration through the slot [4].

Two methods for including the losses associated with good conductors into FDTD thin-slot algorithms are presented in this paper. It is assumed that the losses are primarily due to conduction current on the interior walls of the slot, and therefore, loss is only applied to this reg on. The exterior walls are assumed to be perfectly conducting. The length of the slot is assumed to be much greater than both its width and depth.

The first method uses a surface impedance concept to modify the standard "Hwall" TSF introduced by Taflove [2] and further studied in [3]. This approach defines exterior walls on tangential H-fields by reducing the magnetic-field flux area associated with Faraday's law used to generate the H-field difference equations. As shown in [3], modeling thin slots in FDTD codes in this way works well as long as the slot is an integral number of FDTD cells in depth. If the depth is not an integral number, this

method will underestimate the aperture field because of the inherent averaging over one cell (taken through the slot) in the FDTD code. Underestimation of the aperture fields similarly occurs when external walls are defined using tangential E-fields [3], which is a common way to define walls. 
To accommodate the case where slots may not be an integral number of FDTD cells in depth, the Hybrid Thin-Slot Algorithm (HTSA) was introduced in [3]. This method permits exterior walls to be conveniently defined on tangential E-fields, and can, if necessary, be used in conjunction with a flux-area reduction scheme to properly locate walls that may be some fraction of an FDTD cell in thickness. By using the total FDTD fields local to the slot to create a feedback technique, this method is based on characterizing the slot physics using a "half-space" integralequation formulation. In [4], a frequency-dependent integral equation for describing a linear slot's equivalent magnetic current was derived that permits wall losses and lossy gaskets to be included. A time-dependent version of this equation is used here in conjunction with the hybrid technique to create the second method for accommodating loss in FDTD thin-slot algorithms.

\section{ANALYSIS}

\section{A. Direct Inclusion into FDTD Equations}

A section of a linear slot of length $\mathrm{L}$, depth $\mathrm{d}$ and width $\mathrm{w}$ is shown in Fig. 1. An H-wall FDTD mesh $[2,3]$ has been superimposed. The slot is assumed to be one FDT'D cell deep. Note that the FDTD mesh places $\mathrm{E}_{\mathrm{z}_{\mathrm{a}}}$ and $\mathrm{H}_{\mathrm{y}_{\mathrm{a}}}$ cornponents within the slot (a subscript "a" will be used to denote FDTD fields inside the slot). For w $<<d$ and $\mathrm{L}$, the $\mathrm{x}$-directed conduction current on the upper and lower surfaces of the slot can be significantly affected by walls that are not perfectly conducting. The $\mathrm{H}_{\mathrm{y}_{\mathrm{a}}}$ term is coupled to this conduction current, and therefore the equation for advancing $\mathrm{H}_{\mathrm{y}_{\mathrm{a}}}$ can be modified to include the wall loss effects. The exterior walls are assumed to be perfectly conducting, because slot losses are primarily due to the interior wall current when the slot is long and narrow and the walls are good conductors [4]. 


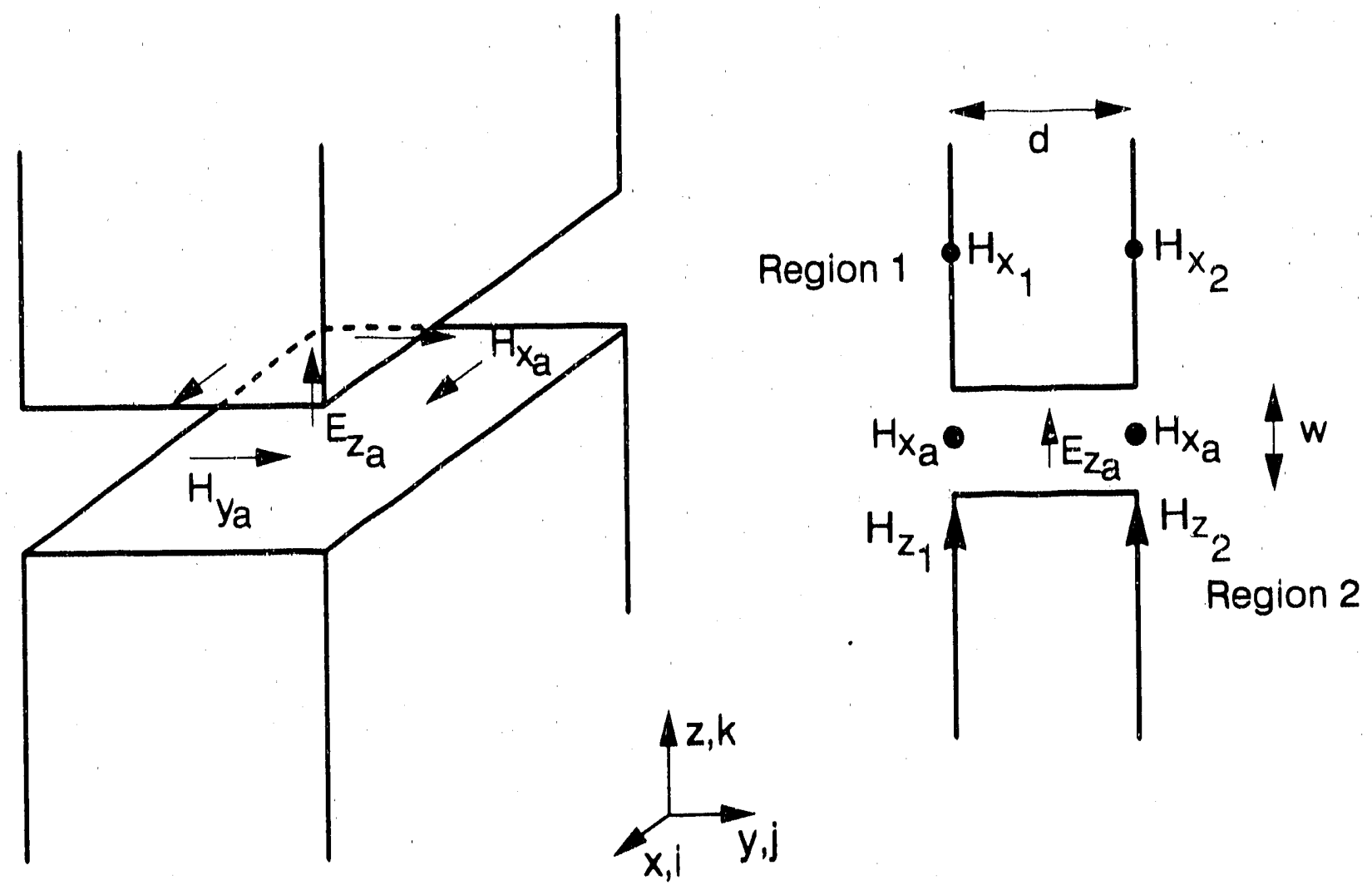

Figure 1: Geometry of a long slot of depth $d$ and width w showing interior FDTD fields. The slot is assumed to be of length $L$ in the $x$ direction and composed of many similar FDT'D cells. Note that tangential $\mathrm{H}$-fields define the entering and exiting planes of the slot (H-wall). 
In the frequency domain, the surface impedance for a good-conducting plane is given by [5]

$$
\mathscr{F}_{\mathrm{S}}(\omega)=\sqrt{ }\left(\mathrm{j} \omega \mu_{\mathrm{O}} / \sigma\right)
$$

where $\omega$ denotes the radian frequency, $\sigma$ denotes the wall conductivity and $\mu_{0}$ denotes the permeability of free space. This expression is valid as long as $\left|\sigma /\left(j \omega \epsilon_{0}\right)\right|>>1$, where $\epsilon_{0}$ denotes the permittivity of free space. An $\exp (j \omega t)$ dependence is assumed. The total tangential electric field can be written in terms of this impedance and the surface-current density, $\bar{J}_{S}(\omega)$, or equivalently, in terms of the surface magnetic field, $\overline{\mathscr{F}}_{\mathrm{S}_{\mathrm{a}}}$, as $\hat{\mathrm{n}} \times \overline{\mathscr{E}}_{\mathrm{S}_{\mathrm{a}}}=\hat{\mathrm{n}} \times\left(\mathscr{Z}_{\mathrm{S}} \overline{\mathscr{F}_{\mathrm{S}}}\right)=\mathscr{Z}_{\mathrm{S}} \hat{\mathrm{n}} \times\left(\hat{\mathrm{n}} \times \overline{\mathscr{F}}_{\mathrm{S}_{\mathrm{a}}}\right)$.

For the narrow slot in Fig. 1, $\not b_{y_{a}}$ is essentially uniform across the width, and therefore the $x$-directed electric field on the upper and lower surfaces of the slot are approximately given by $\mathscr{E}_{\mathrm{x}_{\mathrm{a}}}(\omega) \cong \pm \mathscr{F}_{\mathrm{s}}(\omega) \mathscr{F}_{\mathrm{y}_{\mathrm{a}}}(\omega)$, where the "plus" and "minus" signs are for the upper and lower surfaces, respectively. In the time domain, this expression becomes a convolution given by [5]

$$
\mathrm{E}_{\mathrm{x}_{\mathrm{a}}}(\mathrm{t}) \cong \pm \int_{0}^{\mathrm{t}} \mathrm{d} \tau \sqrt{\frac{\mu_{0}}{\pi \sigma \tau}} \frac{\partial}{\partial \tau} \mathrm{H}_{\mathrm{y}_{\mathrm{a}}}(\mathrm{t}-\tau)
$$

Now consider the Maxwell equation for $\mathrm{H}_{\mathrm{y}_{\mathrm{a}}}$,

$$
\mu_{0} \frac{\partial}{\partial t} H_{y_{a}}(t)=\frac{\partial}{\partial x} E_{z_{a}}-\frac{\partial}{\partial z} E_{x_{a}}
$$

and the contour shown in Fig. 2. By assuming $\mathrm{H}_{\mathrm{y}_{\mathrm{a}}}$ is a constant within the area bounded by the contour, $\mathrm{E}_{\mathbf{x}_{\mathrm{a}}}$ is constant along the entire upper and lower legs, and $\mathrm{E}_{\mathrm{z}_{\mathrm{a}}}$ is constant across the gap, the following FDTD equation for (3) is obtained: 


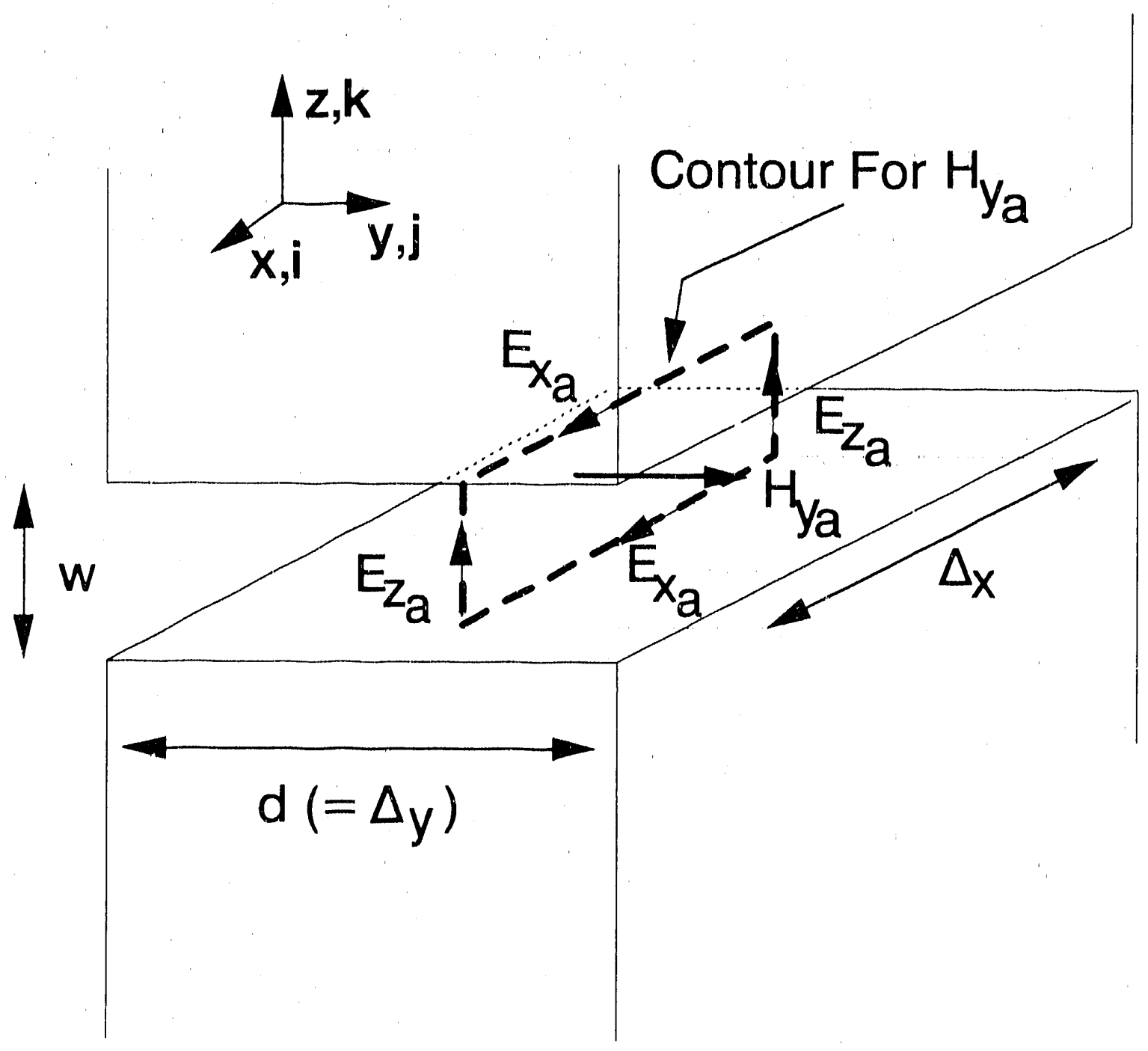

Figure 2: Contour used to include wall loss into the FDTD equation for advancing $\mathrm{H}_{\mathrm{y}_{\mathrm{a}}}$. This contour is unique to the interior of the slot. For simplicity, the depth is assumed to be one FDTD cell. 


$$
\begin{gathered}
H_{y_{a}}^{n}(i, j, k)=H_{y_{a}}^{n-1}(i, j, k)+\frac{\Delta t}{\mu_{0}} \frac{E_{z_{a}}^{n-1}(i, j, k)-E_{z_{u}}^{n-1}(i-1, j, k)}{\Delta x} \\
\frac{\Delta t}{\mu_{0}} \frac{E_{x_{a}}^{n-1}(i, j, k)-E_{x_{a}}^{n-1}(i, j, k-1)}{w}
\end{gathered}
$$

This equation is assumed to be centered at time $\left(n-\frac{1}{2}\right) \Delta t$ and gives $H_{y_{a}}$ at $n \Delta t$. Observe that although a generic-index $\mathrm{n}$ is used for the time step, the $\mathrm{E}$ - and H-fields are separated in time by $\Delta t / 2$. The $H$-fields are assumed to be advanced before the $E-$ fields, which is the convention followed by the FDTD-code THREDH [6]. When the walls are perfectly conducting, the $\mathrm{E}_{\mathrm{x}_{\mathrm{a}}}$ contribution vanishes. For imperfectly conducting walls, $\mathrm{E}_{\mathrm{x}_{\mathrm{a}}}$ is generally an unknown that could only be determined if the FDTD spatial mesh could resolve at least a skin depth at the highest frequency of interest, which is, of course, not practical for microwave coupling problems. As long as $\mathrm{d}>\mathrm{w}>>\delta$, where $\delta$ denotes the skin depth at the highest desired frequency, Eq. (2) can be used to represent the $\mathrm{E}_{\mathrm{x}_{\mathrm{a}}}$ terms. Using causality,

$$
\frac{E_{x_{a}}^{n-1}(i, j, k)-E_{x_{a}}^{n-1}(i, j, k-1)}{w} \cong \frac{2}{w} \sum_{n^{\prime}=1}^{n-1} \sqrt{\frac{\mu_{0}}{\pi\left(n^{\prime}-\frac{1}{2}\right) \Delta t}}\left[H_{y_{a}}^{n-n^{\prime}}-H_{y_{a}}^{n-1-n^{\prime}}\right] .
$$

Observe that this expression only involves the known time history of $\mathrm{H}_{\mathrm{y}_{a}}$ at the midpoint of the slot depth (onerell-deep slot assumed). If the slot is several FDTD cells deep, a simila: modification must be applied to each $\mathrm{H}_{y_{a}}$ equation through the depth (and length). It is important to note that the right-hand side of this expression is a replacement for the $\mathrm{E}_{\mathrm{x}_{\mathrm{a}}}$ terms only for the $\mathrm{H}_{\mathrm{y}_{\mathrm{a}}}$ equation in he slot. It should not be used to define $\mathrm{E}_{\mathrm{x}_{\mathrm{a}}}$, because this will possibly lead to non-zero fields within the wall.

To complete the implementation of this algorithm, three additional FDTD equations must be modified. When walls are defined on tangential $\mathrm{H}$-fields, the flux 
area associated with the FDTD equations must be reduced for the cells local to the wall [2]. For the wall shown in Fig. 1, the $\mathrm{H}_{\mathrm{x}_{1,2}}$ and $\mathrm{H}_{\mathrm{z}_{1,2}}$ equations require modification (only the $\mathrm{H}_{\mathrm{x}}$ terms required modification in [2] because of the twodimensional nature of that study). These modifications are inherent in the $\mathrm{H}$--wall method and are required even for the lossless case (cf. Appendix A).

\section{B. Hybrid Thin-Slot Algorithm with Wall Loss and Lossy Gaskets}

For the HTSA, walls within the FDTD mesh can accurately and conveniently be defined on tangential E-fields ("E-wa.l" case [3]). The HTSA characterizes the slot physics using an equivalent magnetic current adjacent to a shorted (perfectly) conducting wall. Figure 3 depicts this configuration. Any loss effects internal to the slot will be reflected in the magnetic current. The development presented here represents an extension of [3].

In reference [4], a frequency-dependent integral equation for the magnetic current was derived for including wall loss and lossy gaskets into narrow slots in an infinitely large, thick, plane with empty half-spaces on each side. The HTSA will permit a time-dependent version of this equation to be integrated into an FDTD code such that the infinite plane and empty half-space restrictions are removed. For the case where the interior losses are large and a non-magnetic gasket fills the entire slot, the inverse transformed integral equation is

$$
\begin{gathered}
\left(\frac{\partial^{2}}{\partial x^{2}}-\frac{1}{c^{2}} \frac{\partial^{2}}{\partial t^{2}}\right) \int_{-L / 2}^{L / 2} d x^{\prime} \frac{K_{x}\left(x^{\prime} ; t-R_{a} / c\right)}{2 \pi R_{a}}-\frac{1}{2} \int_{0}^{t} d \tau y^{i n t}(\tau) \frac{\partial^{2}}{\partial x^{2}} K_{x}(t-\tau)- \\
\frac{1}{2} \frac{d}{w}\left[\mu_{0} \sigma_{g} \frac{\partial}{\partial t} K_{x}(t)+\frac{1}{c^{2}} 2\left(\frac{\epsilon_{g}}{\epsilon_{0}}-1\right) \frac{\partial^{2}}{\partial t^{2}} K_{x}(t)\right]=\mu_{0} \frac{1}{2} \frac{\partial}{\partial t}\left[\left(H_{x}\right)^{S c 2}-\left(H_{x}\right)^{s c 1}\right]
\end{gathered}
$$




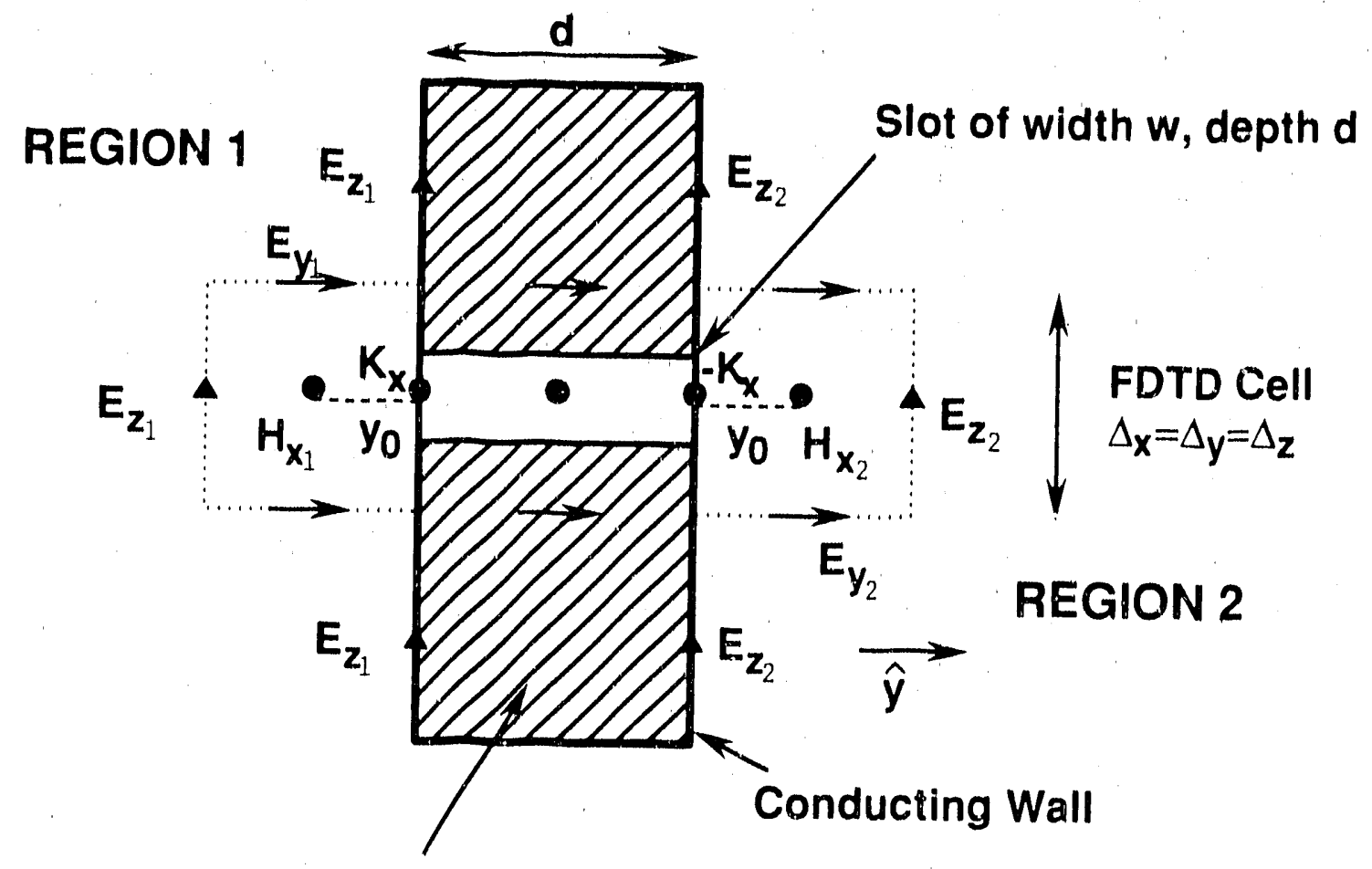

All FDTD fields in the wall are zero when HTSA is used (Including slot region)

Figure 3: FDTD mesh for using the HTSA. Walls defined on tangential E-fields (E-wall). Slot is shorted when HTSA is used. A uniform FDTD cell is assumed with free space in both regions. 
where $R_{a}=\sqrt{ }\left[a^{2}+\left(x-x^{\prime}\right)^{2}\right]$, c denotes the speed of light in vacuum, $\left(H_{x}\right)^{s c 1}$ and $\left(\mathrm{H}_{\mathrm{x}}\right)^{\mathrm{sc2}}$ denote the short-circuit fields in region 1 and region 2 , respectively, $\mathrm{K}$. denotes the total magnetic current, a denotes the equivalent antenna radius for the slot, $\epsilon_{\mathrm{g}}$ represents the permittivity of the gasket and $\sigma_{\mathrm{g}}$ denotes its conductivity ( $c_{\mathrm{g}}$ $<<\sigma$, the wall condactivity). Using the surface impedance given by (1), the term $y^{\text {int }}(t)$ represents the inverse transform of Eq. (76) of [4] (scaled by $j \omega \mu_{0}$, and observing that the time-convention $\exp (-i \omega t)$ was used in [4]):

$$
y^{\text {int }}(t)=\frac{2}{w \sqrt{ }\left(\sigma \mu_{0}\right)} \frac{d}{w}\left[\frac{1}{\sqrt{ }(\pi t)}-\frac{2}{w \sqrt{ }\left(\sigma \mu_{0}\right)} \exp \left[\frac{4 t}{w^{2} \sigma \mu_{0}}\right] \operatorname{erfc}\left[\frac{2}{w \sqrt{ }\left(\sigma \mu_{0}\right)} \sqrt{ } t\right]\right.
$$

Here, erfc $(\cdot)$ denotes the complementary error functior.

The magnetic current in (4), and the ragnetic-current density, $M_{x}$, are related by $K_{x}(x ; t)=L_{w / 2}^{w / 2} d z M_{x}(x, z ; t)$. Since $\hat{y}$ is assumed to be directed into region $2, \mathrm{M}_{\mathrm{x}}$ in region 1 is related to the transverse electric field in the gap, $\mathrm{E}_{\text {gap }}$, by $\hat{\mathrm{x}} \mathrm{M}_{\mathrm{x}}=$ $\hat{y} \times\left(\hat{z} E_{\text {gap }}\right)$. In region 2 , the magnetic-current density changes sign. Observe that the average electric field across the gap can be written as $K_{x} / w$.

The equivalent radius $a=(w / 4) \exp [-\pi d /(2 w)]$ is used in (4) [7]. This requires: 1) $\mathrm{L} / \mathrm{w}>>1$; and 2 ) $\mathrm{w}$ and $\mathrm{d}$ are both electrically small at the highest frequency of interest. Observe that slot depth resonances (and transit times through the depth) are ignored by this formulation and that $\mathrm{E}_{\text {gap }}$ is assumed to be uniform throughout the gap depth. It is noted that many practical narrow apertures are much longer than either their width or depth; thus, ignoring depth resonances will only be a problem if the illumination has sufficient high-frequency content to excite these resonances. However, such high frequencies may not be resolvable in a practical FDTD model because of frequency limitations imposed by the largest cell size.

Because the FDTD mesh places external $\mathrm{H}$-fields a distance $\mathrm{y}_{0}$ from the wall, 
the short-circuit fields in region 1 can be approximated as [3]

$$
\left(\mathrm{H}_{\mathrm{x}}\right)^{\mathrm{sc1} \cong \mathrm{H}_{\mathrm{x}_{1}}-H_{\mathrm{x}_{1}}}
$$

where $\mathrm{H}_{\mathbf{x}_{1}}$ denotes the total $\mathrm{x}$-directed FDTD field in region 1 , and $H_{\mathrm{x}_{1}}$ denotes the halfspace field radiated by the magnetic line source positioned against the wall and evaluated at spatial-position $\mathrm{y}_{\mathrm{O}}$. The half-space contribution obeys the following standard expression $(-\mathrm{L} / 2 \leq \mathrm{x} \leq \mathrm{L} / 2)$ :

$$
\mu_{0} \frac{\partial}{\partial t} H_{x_{1}}\left(x, y_{0} ; t\right)=\left(\frac{\partial^{2}}{\partial x^{2}} 2^{-\frac{1}{c^{2}}} \frac{\partial^{2}}{\partial t^{2}}\right) \int_{-L / 2}^{L / 2} \mathrm{dx} x^{\prime} \frac{\mathrm{K}_{\mathrm{x}}\left(\mathrm{x}^{\prime} ; \mathrm{t}-\mathrm{R}_{\mathrm{y}_{0}} / \mathrm{c}\right)}{2 \pi \mathrm{R}_{\mathrm{y}_{0}}}
$$

where $\mathrm{R}_{\mathrm{y}_{0}}=\sqrt{ }\left[\mathrm{y}_{0}{ }^{2}+\left(\mathrm{x}-\mathrm{x}^{\prime}\right)^{2}\right], \mathrm{y}_{\mathrm{O}}>>$ a. An approximation to the short-circuit term for region 2 is similar (the right side of (6) differs by a minus sign).

To solve equation (4) using a finite-difference scheme, $\mathrm{K}_{\mathrm{x}}$ is expanded as

$$
\mathrm{K}_{\mathrm{x}}\left(\mathrm{x}^{\prime} ; \tau\right)=\sum_{\mathrm{i}^{\prime}=1}^{\mathrm{N}} \sum_{\mathrm{n}^{\prime}=-\infty}^{\infty} \mathrm{K}_{\mathrm{i}^{\prime}}^{\mathrm{n}^{\prime}}, \mathrm{P}_{\Delta t}\left(\tau-\left[\mathrm{n}^{\prime}-\frac{\mathrm{t}}{2}\right] \Delta \mathrm{t}\right) \mathrm{P}_{\Delta}\left(\mathrm{x}^{\prime}-\mathrm{i}^{\prime} \Delta\right),
$$

where $\Delta$ defines the spatial step along the axis of the slot, equal to $L /(N+1)$, and $\Delta t$ denotes the time step. It is noted that $\Delta$ is not required to be equal to the spatial step used in the main FDTD code; further comments on this will be made below. $\mathrm{P}_{\Delta \mathrm{t}}$ and ${ }^{P_{\Delta}}$ denote standard unit pulse functions with widths $\Delta t$ and $\Delta$, respectively. $K_{i}^{n}$ denotes the unknown coefficients at spatial position i $\Delta$ and time $\left(n-\frac{1}{2}\right) \Delta t$. A half time step is used so that the magnetic-current elements will align with the E-fields in the FDTD-code THREDH. 
With the expansion for $\mathrm{K}_{\mathrm{X}}$, an approximation to the retarded-time integral in (4) involving $R_{a}$ is

$$
\left.\int_{-L / 2}^{L / 2} d x^{\prime} \frac{K_{x}\left(x^{\prime} ; t-R_{a} / c\right)}{2 \pi R_{a}}\right|_{\substack{x=i \Delta \\ t=\left(n-\frac{1}{2}\right) \Delta t}} \cong \sum_{i^{\prime}=1}^{N} K_{i^{\prime}}^{n-\left|i-i^{\prime}\right|} G_{\left|i-i^{\prime}\right|}^{a}
$$

where

$$
\mathrm{G}_{\alpha}^{\mathrm{a}}=\frac{1}{2 \pi} \ln \left[\frac{\left.\left(\alpha+\frac{1}{2}\right) \Delta+\sqrt{ }\left(\alpha+\frac{1}{2}\right)^{2} \Delta^{2}+\mathrm{a}^{2}\right]}{\left.\left(\alpha-\frac{1}{2}\right) \Delta+\sqrt{ }\left(\alpha-\frac{1}{2}\right)^{2} \Delta^{2}+\mathrm{a}^{2}\right]}\right]
$$

$\mathrm{n}=1,2,3, \ldots, \mathrm{i}=1,2, \ldots, \mathrm{N}$, and $\mathrm{a}<<\Delta$. This expression has used $\mathrm{n}^{\prime}=\mathrm{n}-\left|\mathrm{i}-\mathrm{i}^{\prime}\right|$, which assumes $c \Delta t=\Delta$ for the slot-solution algorithm.

The spatial integral involving $\mathrm{R}_{\mathrm{y}_{0}}$ (Eq. (6)) is similar, but formally requires a more general evaluation because of the significant non-uniform time retardation for $a<y_{0} \leq \Delta$. Using the simple weighting function $\left.\beta_{\left|i-i^{\prime}\right|}=\mathbb{l}\left(y_{0} / \Delta\right)^{2}+\left(i-i^{\prime}\right)^{2}\right]-$ $\left|i-i^{\prime}\right|$, which is adequate for $y_{O} \cong \Delta$, the integral can be approximated as (cf. Appendix B for a rigorous evaluation)

$$
\sum_{i^{\prime}=1}^{N}\left[\beta_{\left|i-i^{\prime}\right|} K_{i^{\prime}}^{n-1-\left|i-i^{\prime}\right|}+\left(1-\beta_{\left|i-i^{\prime}\right|}\right) K_{i}^{n-\left|i-i^{\prime}\right|}\right] G_{\left|i-i^{\prime}\right|}^{y_{0}}
$$

Here, $\mathrm{G}_{\alpha}^{\mathrm{y}_{0}}$ is the same as $\mathrm{G}_{\alpha}^{\mathrm{a}}$ with a replaced by $\mathrm{y}_{0}$. (It is noted that for practical purposes, the weighting between two time steps has been found to be non-essential as iong as a $<<\mathrm{y}_{\mathrm{O}^{\prime}}$; i.e., simply using $\Sigma \mathrm{K}_{\mathrm{i}}^{\mathrm{n}-\left|\mathrm{i}-\mathrm{i}^{\prime}\right|} \mathrm{G}_{\alpha}^{\mathrm{y}_{0}}$ has been found to be sufficient).

By substituting (5) with (6), and a similar expression for region 2, into (4), and then using central differences for all second-order derivatives associated with $K_{x}$. and also the derivatives associated with the short-circuit H-fields, and backward differences for the first-order derivative on $\mathrm{K}_{\mathrm{X}}$, the following explicit scheme is 
obtained for the coefficients $K_{i}^{n}$ :

$$
\begin{aligned}
& K_{i}^{n}=\frac{Q_{0}}{T_{0}}\left[K_{i+1}^{n-1}+K_{i-1}^{n-1}-K_{i}^{n-2}\right]+\frac{1}{2} \eta_{0} \stackrel{\Delta}{T}_{0}\left[\left(H_{x_{1}}^{n-1}-H_{x_{1}}^{n-2}\right)-\left(H_{x_{2}}^{n-1}-H_{x_{2}}^{n-2}\right)\right]+ \\
& \mathrm{N}+1 \\
& \frac{1}{T_{0}} \sum_{i=0}^{N}\left[G_{\left|j-i^{\prime}\right|^{2}}^{a}-\left(1-\beta_{\left|i-i^{\prime}\right|}\right) G_{\left|i-i^{\prime}\right|}^{y_{0}}\right]\left[K_{i^{\prime}+1}^{n-1-\left|i-i^{\prime}\right|}+K_{i^{\prime}-1}^{n-1-\left|j-i^{\prime}\right|}-\right. \\
& i \neq i \text {, } \\
& \left.K_{i}^{n-\left|i-i^{\prime}\right|}-K_{i^{\prime}}^{n-2-\left|i-i^{\prime}\right|}\right]-\frac{1}{T_{0}} \sum_{i^{\prime}=0}^{N+1} \beta_{\left|i-i^{\prime}\right|} G_{\mid i-i^{\prime}}^{y_{0}} \mid\left[K_{i^{\prime}+1}^{n-2-\left|i-i^{\prime}\right|}+\right. \\
& \left.K_{i}^{n--2-\left|i-i^{\prime}\right|}-K_{i^{\prime}}^{n-1-\left|i-i^{\prime}\right|}-K_{i^{\prime}}^{n-3-\left|i-i^{\prime}\right|}\right]- \\
& n-1 \\
& \frac{1}{2} \frac{\Delta t}{T_{0}} \sum_{n^{\prime}=1}^{n-1} y^{i n t}\left(\left(n^{\prime}-\frac{t}{2}\right) \Delta t\right)\left[K_{i+1}^{n-n^{\prime}}+K_{i-1}^{n-n^{\prime}}-2 K_{i}^{n-n^{\prime}}\right]- \\
& \frac{1}{2} \frac{\mathrm{d}}{\mathrm{w}} \frac{1}{T_{0}}\left[\eta_{0} \sigma_{\mathrm{g}} \Delta\left(\mathrm{K}_{\mathrm{i}}^{\mathrm{n}-1}-\mathrm{K}_{\mathrm{i}}^{\mathrm{n}-2}\right)+\left(\frac{\epsilon_{\mathrm{g}}}{\epsilon_{0}}-1\right)\left(\mathrm{K}_{\mathrm{i}}^{\mathrm{n}-2}-2 \mathrm{~K}_{\mathrm{i}}^{\mathrm{n}-1}\right)\right]
\end{aligned}
$$

where $Q_{0}=G_{0}^{\mathrm{a}}-\left[1-\beta_{0}\right] G_{0}^{y_{0}}, T_{0}=Q_{0}+\frac{d}{2 \mathrm{w}^{\prime}}\left(\frac{\epsilon_{\mathrm{g}}}{\epsilon_{0}}-1\right), \eta_{0}$ denotes the impedance of free space, $n=1,2, . .$, and $i=1,2, . ., N$. Note that $Q_{0} \cong G_{0}^{a}$ when $y_{0} \cong \Delta$. Eq. (7) is centered at time $\left[(n-1)-\frac{1}{2}\right] \Delta t$ and provides the magnetic current at $\left(n-\frac{1}{2}\right) \Delta t$. It is assumed that $c \Delta t=\Delta$. End conditions require the currents $K_{0}^{\xi}, K_{-1}^{\xi}, K_{N+1}^{\xi}$, and $K_{N+2}^{\xi}$ be defined to be zero for every $\xi$ (all time). In addition, $\mathrm{K}_{\nu}^{\xi}$ is defined to be zero for every $\nu$ with $\xi \leq 0$. An average value for the electric field across the aperture is obtained by forming $\mathrm{K}_{\mathrm{i}}^{\mathrm{n}} / \mathrm{w}, \mathrm{i}=1,2, . ., \mathrm{N} ; \mathrm{n}=1,2, \ldots$ Eq. (7) includes full exterior and interior coupling to the magnetic current through the FDTD fields and is appropriate for an offset FDTD mesh such that $a<y_{0}, y_{0} \cong \Delta$. The more general coefficients for the $R_{y_{0}}$ integral (cf. Appendix $B$ ) could be used so that (7) is rigorously valid for $a<<y_{0} \leq \Delta$.

It is assumed that $\Delta t$ used by the slot algorithm is identical to the time step used in the main FDTD code. To define the spatial step, it is necessary to consider the 
Courant stability criterion required by each code. Three-dimensional FDTD codes based on the Yee algorithm typically choose a uniform spatial step to be $\Delta_{x} / 2=\Delta_{y} / 2$ $=\Delta_{z} / 2=c \Delta t$. This choice amply satisfies the maximum permitted spatial step required for stability given by $\Delta_{x}=\Delta_{y}=\Delta_{z}=c \Delta t \cdot \sqrt{3}[8]$. As formulated above, the time-marching scheme for the magnetic current takes advantage of the choice $c \Delta t=\Delta$ (a more general solution could be derived, but this will further complicate the form of (7)). The choice $c \Delta t=\Delta$ may be taken because the slot algorithm involves a onedimensional finite-difference solution, and therefore a possible Courant stability criterion is $c \Delta t \leq \Delta$ ior this case (for a discussion on establishing stability criteria for transient integro-differential equation formulations, see refs. $[9,10])$. Using the same $\Delta t$ in the slot algorithm implies that $\Delta=\Delta_{X} / 2$. Thus, the spatial step in the slot algorithm is taken to be half that used in the FDTD code, which in turn specifies $N$. Observe that because the slot integral equation is using twice as many spatial samples along the axis of the slot, the FDTD fields will not match all the required spatial evaluation points. For locations where these fields are not defined, an average value can be taken.

Although Eq. (7) is lengthy, it is straightforward to generate a subroutine to implement it. Once the subroutine is created, the use of the HTSA is appealing because all slot parameters are contained within a single subroutine call. In addition, it is effective when the depth of the slot is less than one FDTD cell, which is a case when the H-wall TSF will fail [3]. For convenience, the implementation of the HTSA is reviewed.

Let the present time step in the main FDTD code be $n-1$. At the completion of this time step a call is made to the HTSA subroutine passing $\mathrm{H}_{\mathrm{x}_{1}}^{\mathrm{n}-1}$ and $\mathrm{H}_{\mathrm{x}_{2}}^{\mathrm{n}-1}$, which represent the latest FDTD fields local to the slot in regions 1 and 2 (cf. Fig. 3). The slot subroutine uses these results in $\mathrm{Eq}$. (7), and returns the magnetic current at time-step $\mathrm{n}$. Once the magnetic current is found, return is made to the main FDTD 
code and the next time step begins. Assuming the walls exterior to the slot are defined on tangential E-fields, the H-fields parallel to the slot are advanced using the following equation which includes the magnetic-current element:

$$
\mathrm{H}_{\mathrm{x}_{1,2}}^{\mathrm{n}}=\mathrm{H}_{\mathrm{x}_{1}, 2}^{\mathrm{n}-1}-\frac{\Delta \mathrm{t}}{\mu_{\mathrm{o}}}\left(\nabla \times E^{\mathrm{n}-1}\right)_{\mathrm{x}_{1,2}} \pm\left(\frac{\Delta \mathrm{t}}{\mu_{\mathrm{o}}} \frac{1}{\Delta_{\mathrm{y}}^{-}}\right)\left(\frac{\mathrm{w}}{\Delta_{\mathrm{z}}}\right)\left(\frac{1}{\mathrm{w}} \mathrm{K}_{\mathrm{i}}^{\mathrm{n}}\right)
$$

Here, the "plus" sign is for region 2 and the "minus" sign is for region 1 . The notation $\left(\nabla \times E^{n-1}\right)_{x_{1,2}}$ denotes the $x$ component of a central-difference approximation to $\nabla \times$ $\mathrm{E}^{\mathrm{n}-1}$ in regions 1 and 2 . Only the $\mathrm{x}$-directed equation is modified because of the assumed slot orientation. The equation is centered at time $\left(n-\frac{1}{2}\right) \Delta t$ and gives the IIfield at $n \Delta t$. The reason the $\left(w / \Delta_{z}\right)$ term appears is because the gap electric field must be defined as an average over the entire wall region contained within the FDTD cells local to the aperture. The modified $\mathrm{H}$-field equation only applies within the cells where the aperture is to exist, both in region 1 and region 2 with the appropriate sign chosen for each region. Observe that Eq. (8) is written for general $\Delta_{y}$ and $\Delta_{z}$; however, it is recalled that the magnetic-currentequation (7) assumes $c \Delta t=\Delta_{X} / 2$. Also note that only half of the $\mathrm{K}_{\mathrm{i}}^{\mathrm{n}}$ terms, e.g., $\mathrm{i}=1,3,5, . ., \mathrm{N}$, are used at each time step because of the spatial over-sampling implemented in the slot algorithm. If the wall thickness is required to be a non-integral number of FDTD cells, then a flux-area reduction must appear in (8) and $\mathrm{a}<\mathrm{y}_{0}<\Delta$ (cf. Appendices $\mathrm{A}$ and $\left.\mathrm{B}\right)$.

\section{NUMERICAL RESULTS AND DISCUSSION}

The preceding two methads were applied to the geometry shown in Fig. 4. The aperture is $5-\mathrm{cm}$ long and its depth is $1 \mathrm{~cm}$. To preserve the slot length between the direct method (method A above), and the HTSA approaches, the placement of the slot on the front face differs by $5 \mathrm{~mm}$ in the $\mathrm{x}$-direction between the methods; this is a 


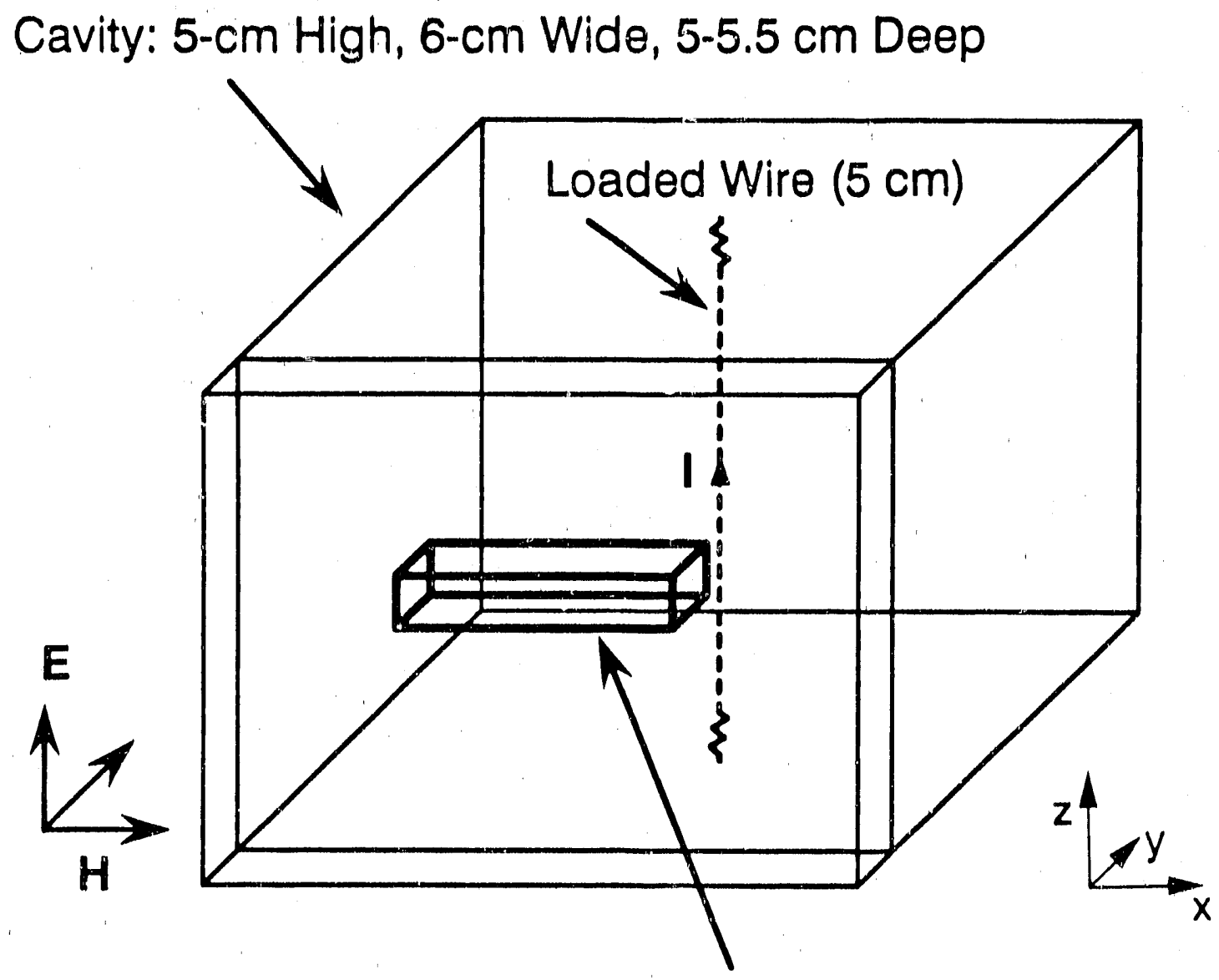

\section{Slot: 5-cm Long, 1-mm or $0.1-\mathrm{mm}$ Wide Walls: $1-\mathrm{cm}$ Thick}

Figure 4: Test geometry for comparing the two loss methods. Wall thicknesses were $1 \mathrm{~cm}$. The cavity depth was $5.5 \mathrm{~cm}$ when the front face was modeled using the $\mathrm{H}$-wall approach and the cell size was $1 \mathrm{~cm}$. Cavity depth was $5 \mathrm{~cm}$ for the HTSA. Slot centered on front face for HTSA solution. Wire loaded with $50 \mathrm{ohms}$ at each end. Only the wall regions inside the slot were assumed to be lossy. 
consequence of the offset FDTD mesh. The comparison point for the slot electric field will be $5 \mathrm{~mm}$ displaced from the slot's midpoirit. The excitation is defined by $\mathrm{E}_{\mathrm{z}}(\mathrm{t})=$ $\exp \left[-\tau_{1}\left(\mathrm{t}-\tau_{2}\right)^{2}\right]$, where $\tau_{1}=6.79 \cdot 10^{19}$ and $\tau_{2}=0.5 \cdot 10^{-9}$. Propagation is y-directed.

Figures 5 and 6 show HTSA slot electric-field results for slot widths of $0.1 \mathrm{~mm}$ and $1 \mathrm{~mm}$ with wall conductivities ranging from $3.5 \cdot 10^{5} \mathrm{~S} / \mathrm{m}$ to perfectly conducting. The reduction in the slot $Q$ is seen to be very significant for the $0.1-\mathrm{mm}$-wide case, but it is only moderately altered for the 1-mm-wide case. The corresponding current at the midpoint of the loaded wire is shown in Figs. 7 and 8 . The spatial cell size in the main FDTD code was $1 \mathrm{~cm}$ for these cases, but recall that the integral equation used in the HTSA provides twice the resolution along the slot length.

In Figs. 9 and 10 is a comparison between the H-wall TSF with the loss modification given by Eqs. (3a) with (3b) and the HTSA solution. As the wall conductivity decreases, it has been found that an ever increasing number of spatial samples are required to adequately resolve the axial slot length. For Figs. 9 and 10, the spatial FDTD cell size was $1 \mathrm{~cm}$. It is seen that the H-wall TSF yields a somewhat lower $\mathrm{Q}$ than the HTSA formulation. At this resolution, the H-wall TSF has only four axial $\mathrm{E}_{\mathrm{z}}$-fields to resolve the length (end points not included), whereas the HTSA is using nine interior magnetic-current samples. The cell size is decreased to $1 / 3 \mathrm{~cm}$ in Fig. 11 and the agreement between the methods is seen to be much better. Note that the HTSA result has not changed significantly at the higher resolution.

The interior walls of the slot are now assumed to have a conductivity of $3.5 \cdot 10^{5} \mathrm{~S} / \mathrm{m}$ and a slot gasket with $\epsilon_{\mathrm{g}}=2 \epsilon_{0}, \sigma_{\mathrm{g}}=0$ is used. The slot is 5-cm long, 1 $\mathrm{cm}$ deep and 0.1-rmm wide (cf. Fig. 4). The FD'TD spatial cell is one $\mathrm{cm}$. Figure 12 compares the electric field $5 \mathrm{~mm}$ displaced from the slot's midpoint with and without the gasket based on the HTSA formulation. The change in period (approximately $\sqrt{ } 2$ longer) corresponds to the expected lowering of the first slot-length resonance. The corresponding spectrums are shown in Figure 13. 


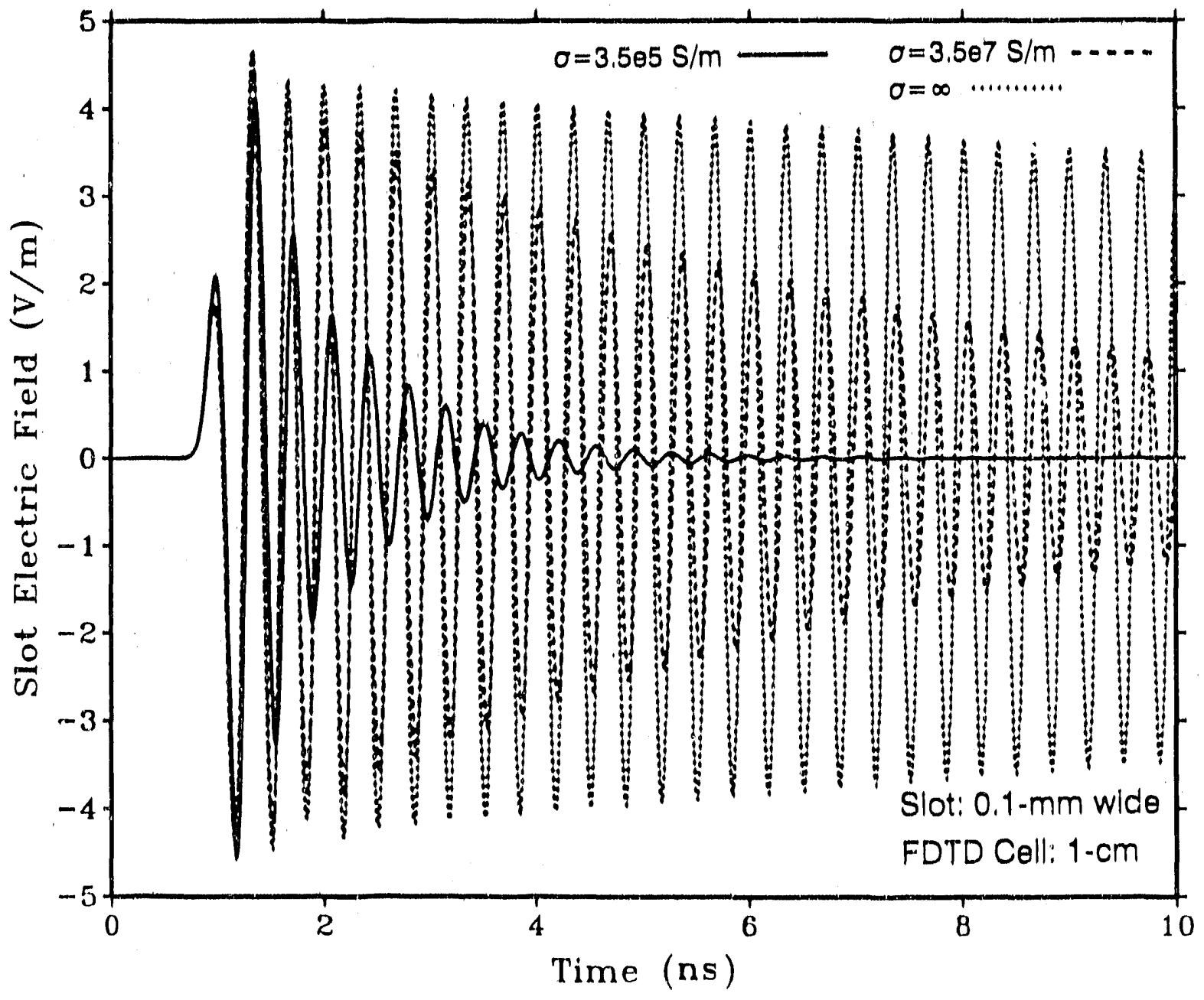

Figure 5: $\quad$ Slot electric field $5 \mathrm{~mm}$ off slot midpoint showing loss effects as the wall conductivity decreases. Slot width: $0.1 \mathrm{~mm}$. Results based on HTSA formulation. 


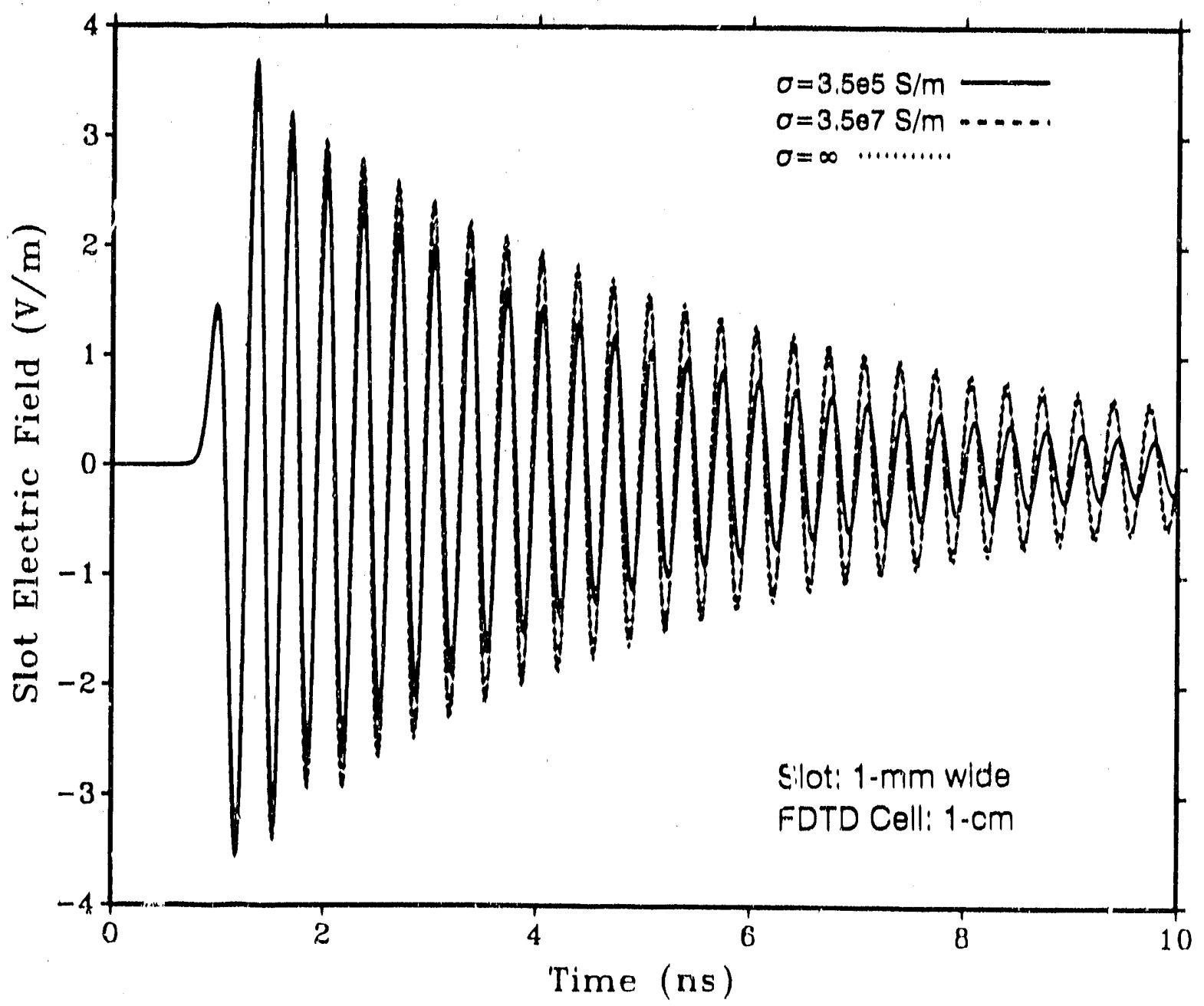

Figure 6: $\quad$ Same as Fig. 5, but with a slot width of $1 \mathrm{~mm}$. 


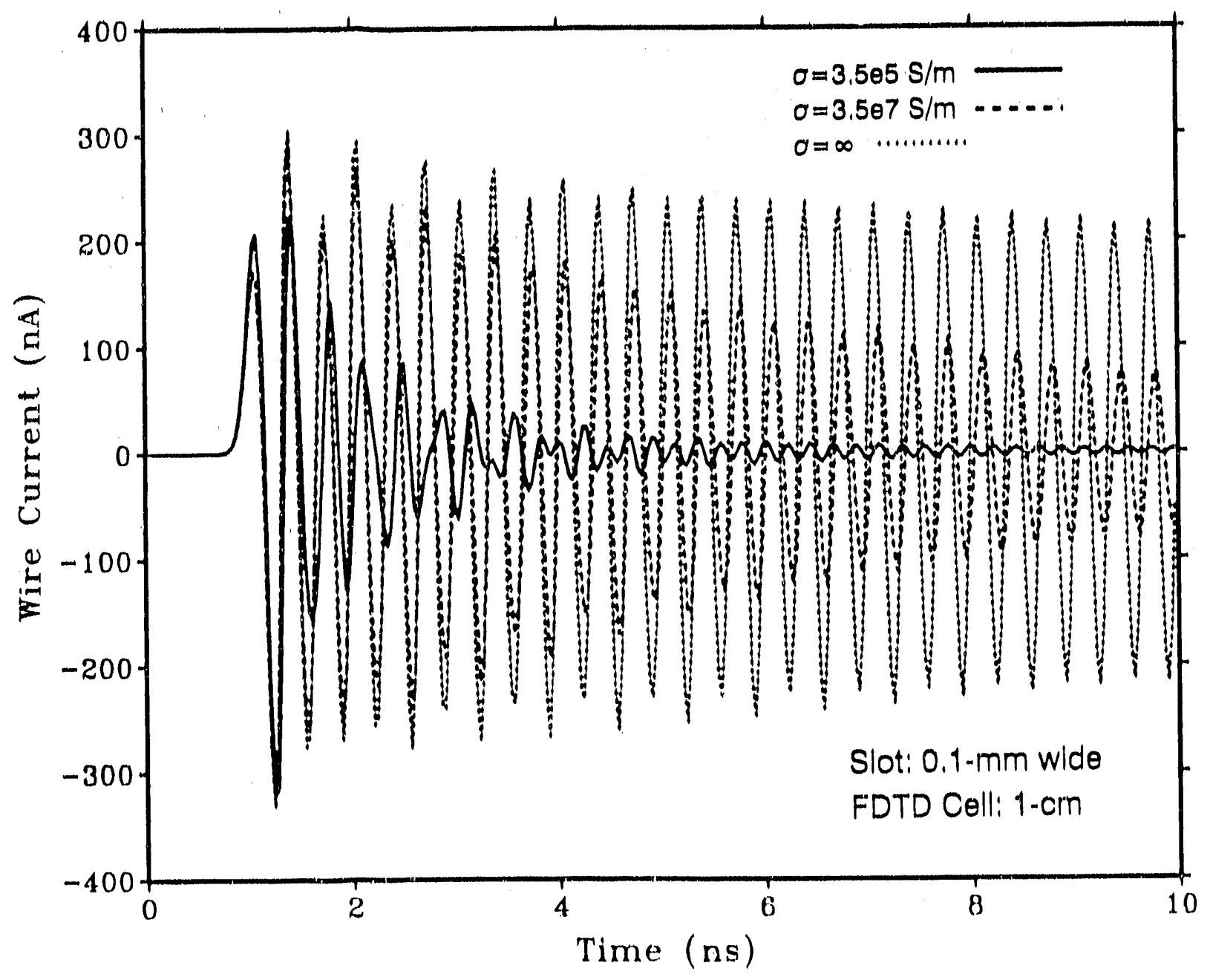

Figure 7: Wire current at wire's midpoint as the slot's wall conductivity decreases. Wire loaded with $50 \mathrm{ohms}$ at its ends. Slot width: $0.1 \mathrm{~mm}$. Wire length: $5 \mathrm{~cm}$. Results based on HTSA formulation. 


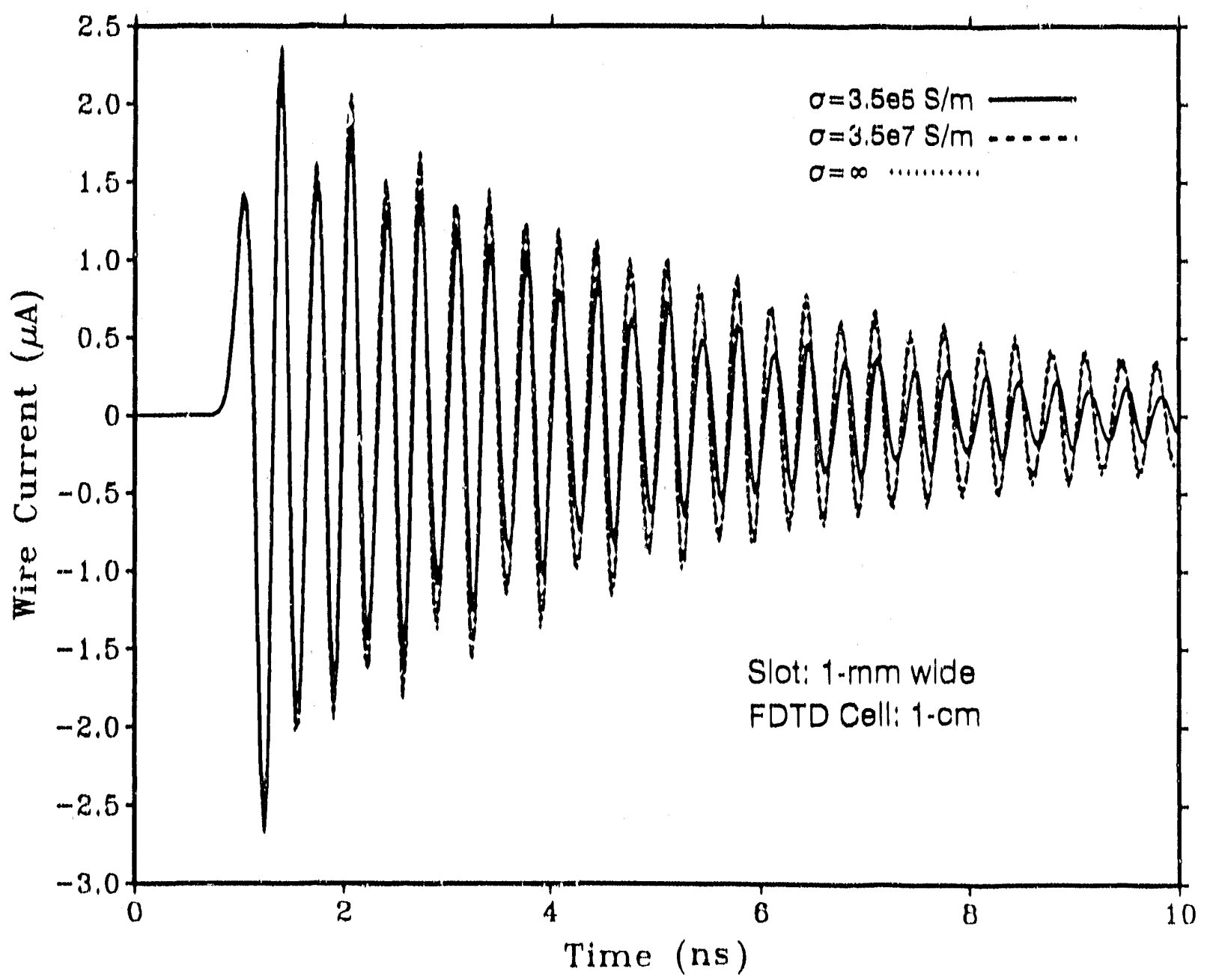

Figure 8: $\quad$ Same as Fig. 7, but with a slot width of $1 \mathrm{~mm}$. 


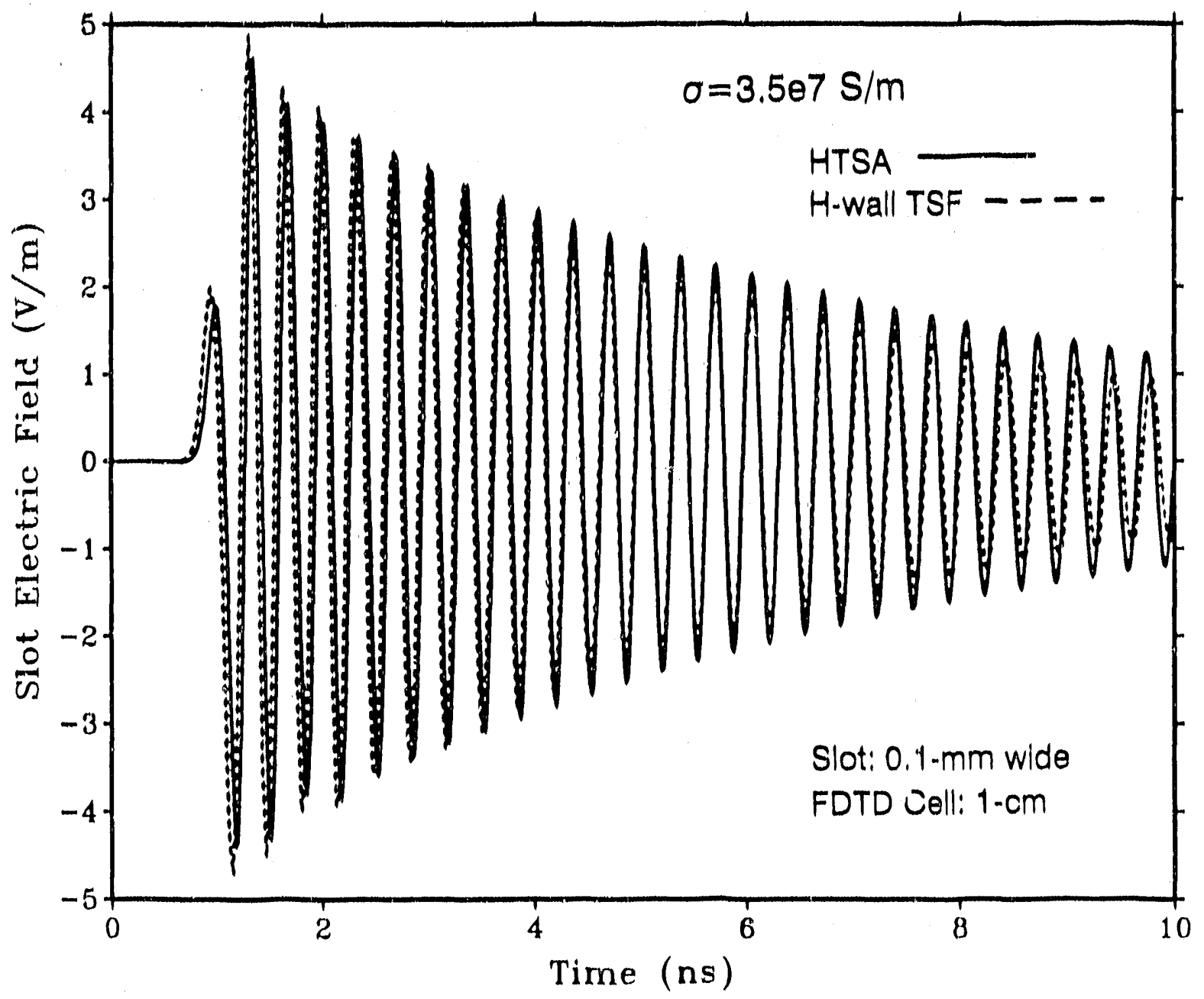

Figure 9: Slot electric field at a position $5 \mathrm{~mm}$ from slot's midpoint. Comparison of the H-wall TSF (with loss) and HTSA for a $0.1-\mathrm{mm}$ wide slot and wall conductivity approximately corresponding to aluminum. One-cm FD'TD cell size. H-wall result at slot's depth midpoint. 


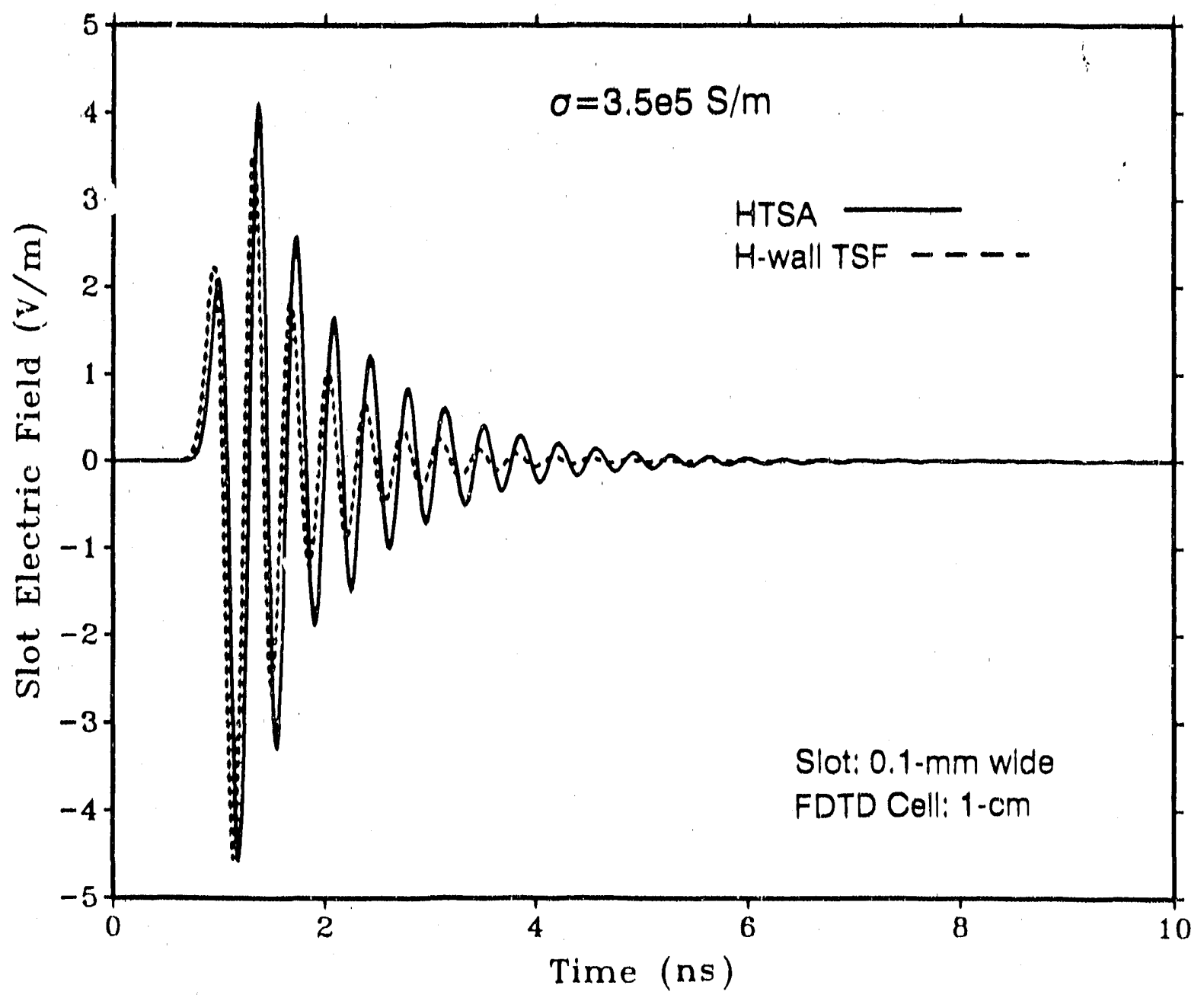

Figure 10: Slot electric field at a position $5 \mathrm{~mm}$ from slot's midpoint. Comparison of the H-wall TSF (with loss) and HTSA for a $0.1-\mathrm{mm}$ wide slot with large wall losses. $1-\mathrm{cm}$ FDTD cell size. H-wall TSF result at slot's depth midpoint. 


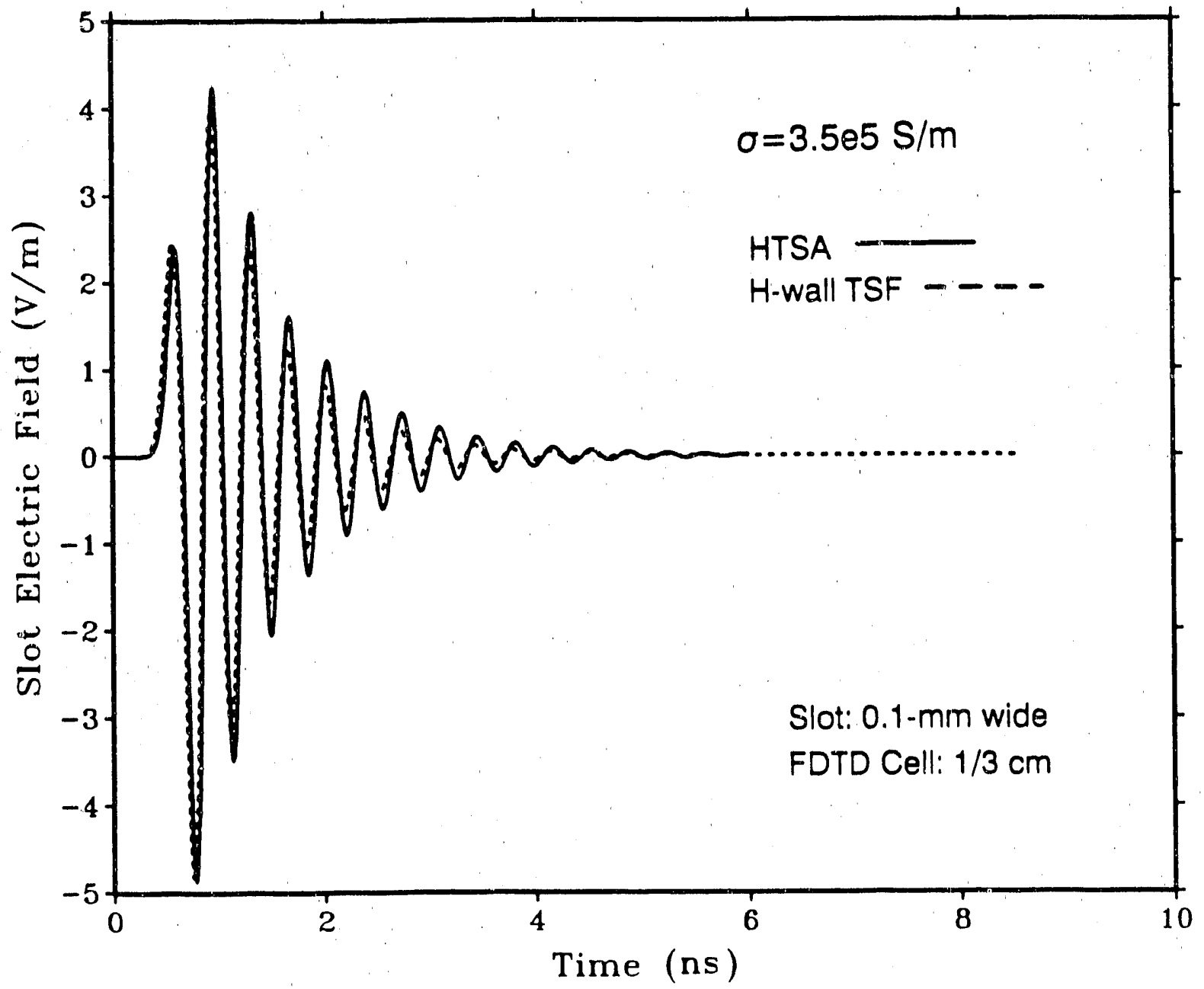

Figure 11: Same as Fig. 10, but with an FDTD cell size of $1 / 3 \mathrm{~cm}$. H-wall TSF result based on E-field closest to the front face of the box. 


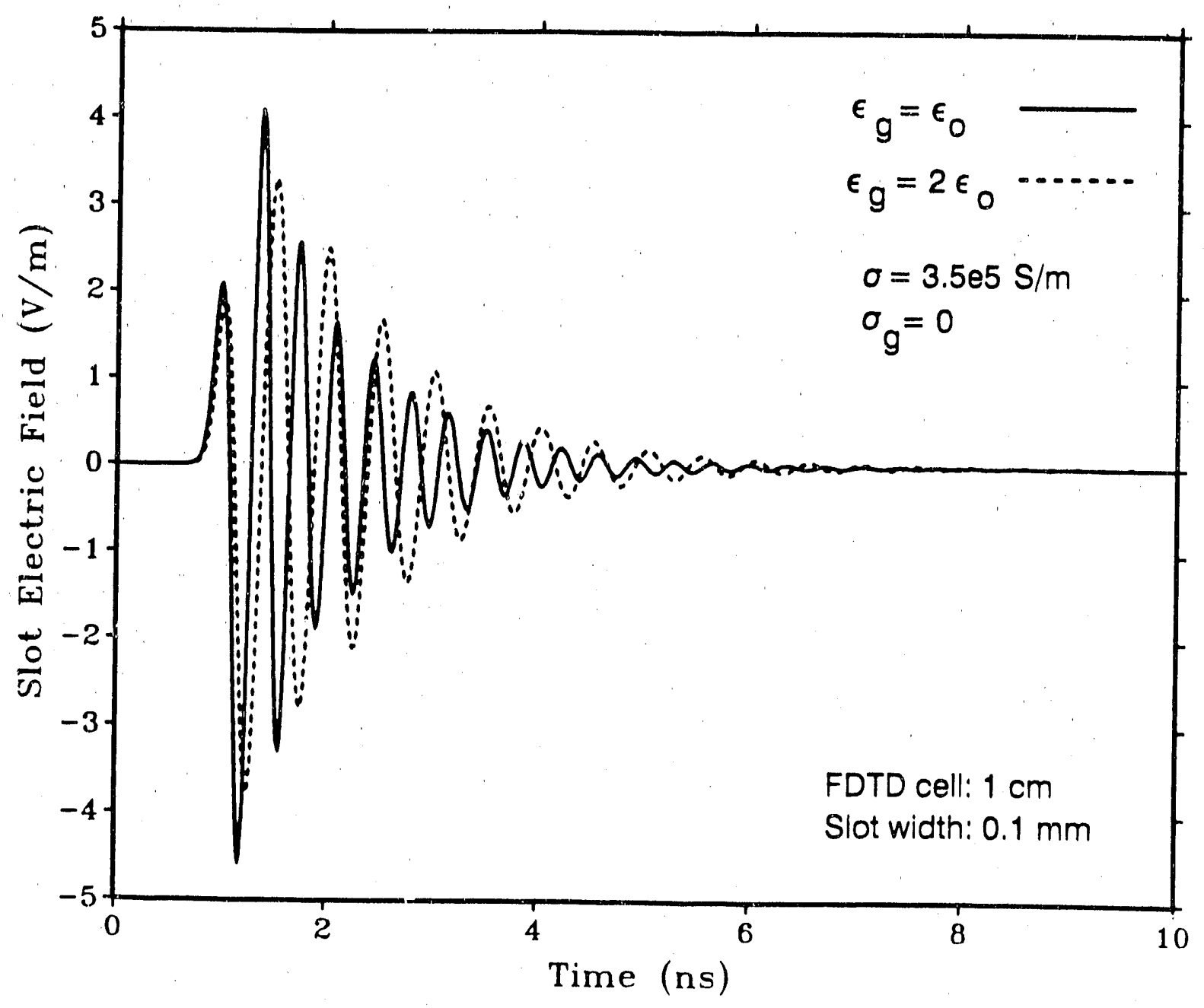

Figure 12: Slot electric field 5-mm off slot's midpoint. Dielectric gasket with $\epsilon_{\mathrm{g}}$ $=2 \epsilon_{0}$ placed in slot. Wall conductivity: $3.5 \mathrm{e} 5 \mathrm{~S} / \mathrm{m}$. Slot width 0.1 $\mathrm{mm}$. Comparison with and without gasket. HTSA formulation. 


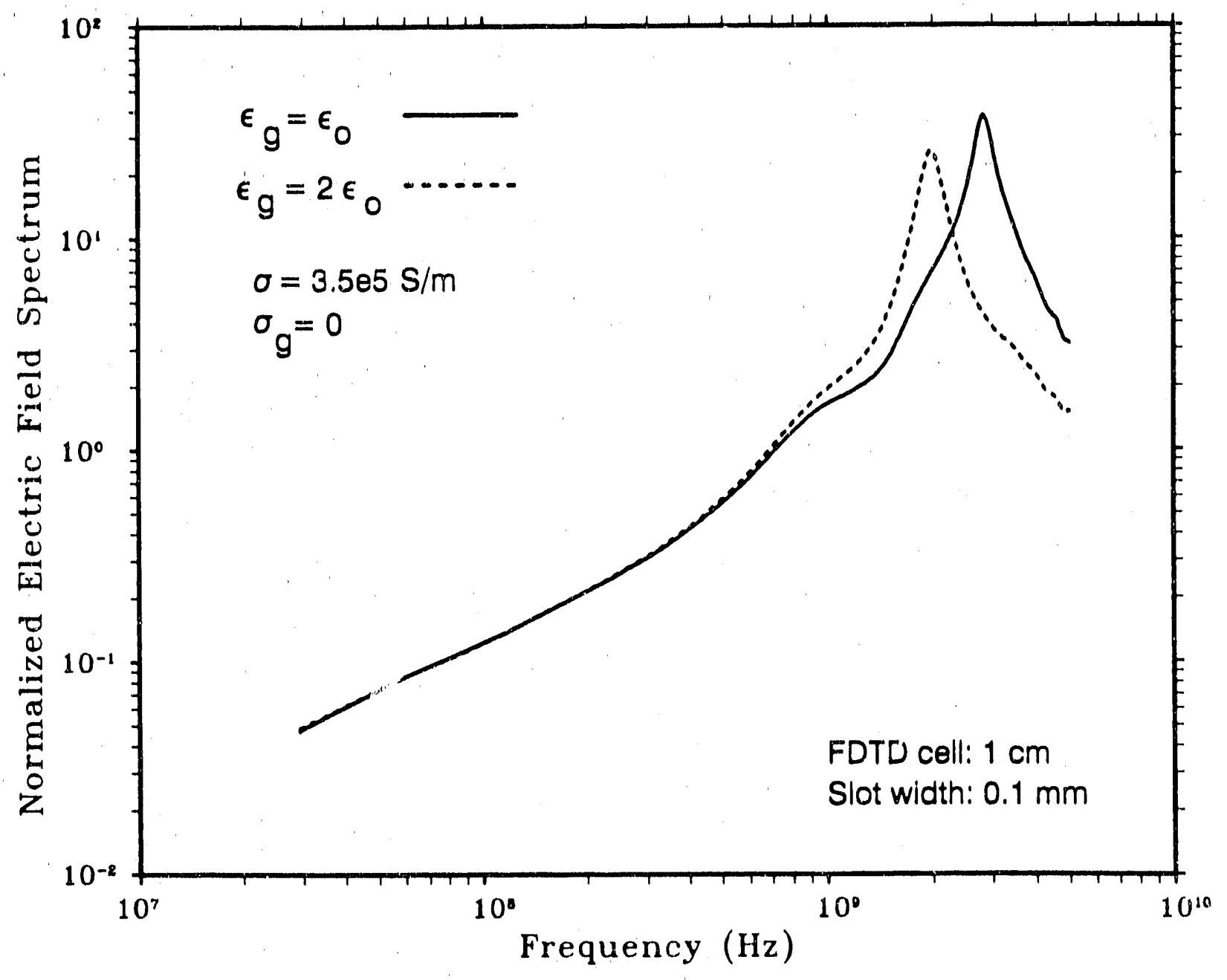

Figure 13: $\quad$ Spectrum of the curves shown in Fig. 12. 


\section{CONCLUDING REMARKS}

Two methods have been presented for incorporating the effect of wall loss into FDTD thin-slot algorithms. The first method was a direct modification of the H-wall TSF that is useful for slots that are an integral number of FDTD cells in depth. For slots that are less than one cell deep, or, in general, a non-integral number of cells in depth, the HTSA method modified to include loss is effective.

When loss is included, both methods introduce overhead into the FDTD code because a convolution integral must be computed at each time step. In addition, additional memory overhead is introduced because a full time history of certain fields must be retained. On the positive side, however, when the conductivities of realistic materials are included into slots that have a very large depth-to-width ratio $(>1)$, the coupling response may damp out much sooner than in the lossless case, and therefore, the length of the overall computer run could, in fact, be greatly reduced.

\section{REFERENCES}

[1] J. Gilbert and R. Holland, "Implementation of the thin-slot formalism in the finite-difference EMP code THREDII," IEEE Trans. Nucl. Sci., vol. NS-28, 6, pp.4269-4274, Dec. 1981.

[2] A. Taflove, K.R. Umashankar, B.Beker, F. Harfoush, and K.S. Yee, "Detailed FD-TD analysis of electromagnetic fields penetrating narrow slots and lapped joints in thick conducting screens," IEEE Trans. Ant. Prop., vol. AP-36, 2, pp. 247-257, Feb. 1988.

[3] D.J. Riley and C.D. Turner, "Hybrid thin-slot algorithm for the analysis of narrow apertures in finite-difference time-domain calculations," IEEE Trans. Ant. Prop., to be published.

[4] L.K. Warne and K.C. Chen, "Slot aperture having depth and losses described by local transmission line theory," IEEE Trans. EMC, vol. 32, 3, pp. 185-196, August 1990. 
[5] F.M. Tesche, "On the inclusion of loss in time-domain solutions of electromagnetic interaction problems," IEEE T'rans. $E M C$, vol. 32,1 , pp. 1-4, Feb. 1990.

[6] D.E. Merewether and R. Fisher, "Finite difference solution of Maxwell's equation for EMP applications," EMA, Inc., Report: EMA-79-R-4, Albq., NM, April 22, 1980.

[7] L.K. Warne and K.C. Chen, "Equivalent antenna radius for narrow slot aperture having depth," IEEE Trans. Ant. Prop., vol. AP-37, 7, pp. 824-834, July 1989.

[8] A. Taflove and M.E. Brodwin, "Numerical solution of steady-state electromagnetic scattering problems using the tıme-dependent Maxwell's equations," IEEE Trans. Microwave Theory Tech., vol. MTT-23, pp. 623-630, Aug. 1975.

[9] D.J. Riley and W.A. Davis, "Time-domain techniques in the singularity expansion method," AFWL Interaction Note 424, Air Force Weapons Laboratory, Albq. NM, Dec. 1982.

[10] D.J. Riley and W.A. Davis, "Application of an offset mesh for the transient, explicit finite-difference analysis of the perfectly conducting rectangular plate," Radio Science, vol. 20, 5, pp. 1031-1036, Sept.-Oct. 1985.

\section{APPENDIX A:}

\section{Thin-Slot Equations for H-Wall Implementation}

In Fig. $\mathrm{A} 1$ is shown a cross section of a thick wall with contours used to create modified FDTD equations for $\mathrm{H}_{\mathrm{x}}$ components $\left(\mathrm{H}_{\mathrm{z}}\right.$ components are similar). It is assumed that the $\mathrm{H}$-field is a constant within the contour, and the E-fields are constant along the contour segments. The components inside the wall will be zero. For $\mathrm{d}=\mathrm{p} \cdot \Delta_{\mathrm{y}}, \mathrm{p}=1,2, .$. , tangential $\mathrm{H}$-fields are on the surface of the wall. For $\mathrm{d}=0$, the wall is infinitesimally thin and defined on tangential E--fields. For these modified equations to accurately predict coupling through narrow slots, $d$ must be set to $p \cdot \Delta_{y^{\prime}}$ $\mathrm{p}=1,2, \ldots$ If used in conjunction with the HTSA, then the slot is shorted and only the "wall" contours $\left(\mathrm{C}_{1}\right)$ are appropriate. In this case, $0 \leq \mathrm{d}<<\Delta_{\mathrm{y}^{\prime}}$ 


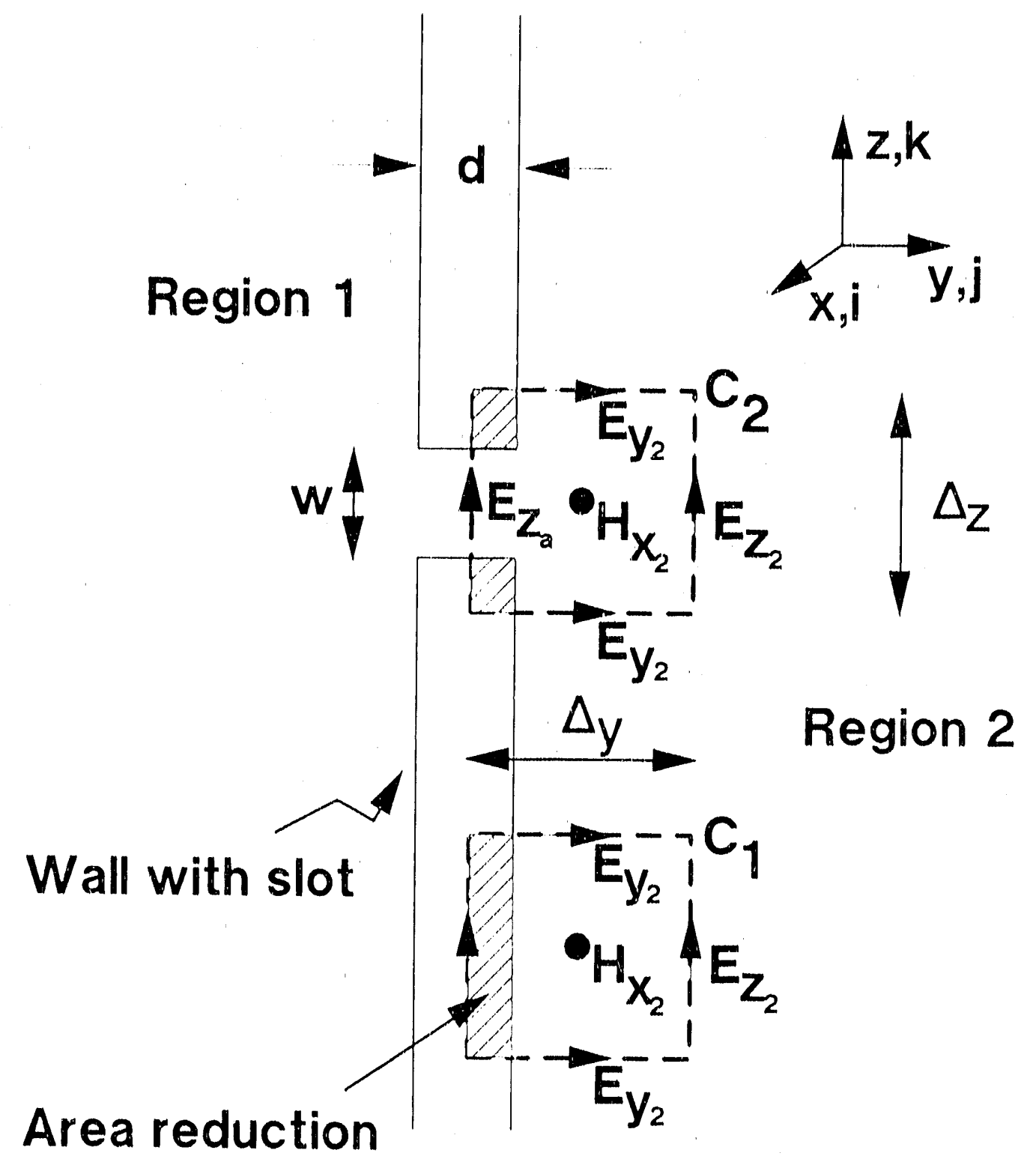

Tigure A1: $\quad$ Contours used to generate an H-wall TSF. 
Contour $\mathrm{C}_{1}$ (Wall, Region 2):

$$
\begin{gathered}
\mathrm{H}_{\mathrm{x}_{2}}^{\mathrm{n}}(\mathrm{i}, \mathrm{j}, \mathrm{k})=\mathrm{H}_{\mathrm{x}_{2}}^{\mathrm{n}-1}(\mathrm{i}, \mathrm{j}, \mathrm{k})+\frac{\Delta t}{\mu_{0}} \frac{\mathrm{E}_{\mathrm{y}_{2}}^{\mathrm{n}-1}(\mathrm{i}, \mathrm{j}, \mathrm{k})-\mathrm{E}_{\mathrm{y}_{2}}^{\mathrm{n}-1}(i, j, k-1)}{\Delta_{z}}- \\
\frac{\Delta t}{\mu_{0}} \frac{\mathrm{E}_{z_{2}}^{\mathrm{n}-1}(\mathrm{i}, \mathrm{j}, \mathrm{k})-\mathrm{E}_{z_{2}}^{\mathrm{n}-1}(\mathrm{i}, \mathrm{j}-1, \mathrm{k})}{\Delta_{\mathrm{y}}-\mathrm{d} / 2}
\end{gathered}
$$

Region 1 contour's give rise to a similar expression.

Contour $\mathrm{C}_{2}$ (Gap, Region 2):

$$
\begin{gathered}
H_{x_{2}}^{n}(i, j, k)=H_{x_{2}}^{n-1}(i, j, k)+\frac{\Delta t}{\mu_{0}} \frac{E_{y}^{n-1}(i, j, k)-E_{y_{2}}^{n-1}(i, j, k-1)}{\left[\Delta_{z}\left(\Delta_{y}-d / 2\right)+w d / 2\right]}\left(\Delta_{y}-d / 2\right)- \\
\frac{\Delta t}{\mu_{0}} \frac{E_{z_{2}}^{n-1}(i, j, k) \Delta_{z}-E_{z_{2}}^{n-1}(i, j-1, k) w}{\left[\Delta_{z}\left(\Delta_{y}-d / 2\right)+w d / 2\right]}
\end{gathered}
$$

For similar contours in region 1 , it is necessary to interchange $w$ and $\Delta_{z}$ which multiply the $\mathrm{E}_{\mathrm{z}_{2}}^{\mathrm{n}-1}$ terms and then replace the subscript $2 \mathrm{~s}$ with subscript $1 \mathrm{~s}$.

The region 1 and $2 \mathrm{H}_{\mathrm{z}}$ components require modification only on the wall regions. In region 2 , the general equation along the wall is

$$
\begin{gathered}
H_{z_{2}}^{n}(i, j, k)=H_{z_{2}}^{n-1}(i, j, k)+\frac{\Delta t}{\mu_{0}} \frac{E_{x_{2}}^{n-1}(i, j, k)-E_{x_{2}}^{n-1}(i, j-1, k)}{\Delta_{y}-d / 2}- \\
\frac{\Delta t}{\mu_{0}} \frac{E_{y_{2}}^{n-1}(i, j, k)-E_{y_{2}}^{n-1}(i-1, j, k)}{\Delta_{x}}
\end{gathered}
$$

Lugion 1 is similar. 


\section{APPENDIX B:}

Evaluation of Retarded-Time Integral for $a<y_{0} \leq \Delta$

The time pulse of interest is given by $\mathrm{P}_{\Delta t}\left(\tau-\left[\mathrm{n}^{\prime}-t\right] \Delta t\right)$, where $\tau=t-$ $\frac{1}{c} /\left[y_{0}^{2}+\left(x-x^{\prime}\right)^{2}\right]$. The pulse is defined by

$$
\mathrm{P}_{\Delta t}(\cdot)=\left[\begin{array}{ll}
1 & (\tau-\Delta t / 2) \leq\left(\mathrm{n}^{\prime}-\frac{1}{2}\right) \Delta t<(\tau+\Delta t / 2) \\
0 & \text { otherwise }
\end{array}\right.
$$

Time and space are discretized as $t=(n-t) \Delta t, x=1 \Delta$. Evaluation of the integral

$$
\begin{aligned}
\int_{-L / 2}^{L / 2} d x^{\prime} \frac{P_{\Delta t}\left(\left(n-\frac{1}{2}\right) c \Delta t-\sqrt{ }\left[y_{0}{ }^{2}+\left(i \Delta-x^{\prime}\right)^{2}\right]-\left(n^{\prime}-\frac{1}{2}\right) c \Delta t\right) P_{\Delta}\left(i \Delta-x^{\prime}\right)}{2 \pi \sqrt{ }\left[y_{0}{ }^{2}+\left(i \Delta-x^{\prime}\right)^{2}\right]}= \\
=\int_{\left(\left|i-i^{\prime}\right|-\frac{t}{2}\right) \Delta}^{\left(\left|i-i^{\prime}\right|+\frac{1}{2}\right) \Delta} d u \frac{P \Delta t\left(\left(n-n^{\prime}\right) c \Delta t-\sqrt{ }\left[y_{0}{ }^{2}+u^{2}\right]\right)}{2 \pi \sqrt{ }\left[y_{0}^{2}+u^{2}\right]},
\end{aligned}
$$

$\mathrm{i}, \mathrm{i}^{\prime}=1,2, \ldots, \mathrm{N} ; \mathrm{n}, \mathrm{n}^{\prime}=1,2, \ldots, \mathrm{a}<\mathrm{y}_{0} \leq \Delta$, is required.

Assuming $c \Delta t=\Delta$, it is easily seen that for $y_{0}<\Delta$ the time pulse is centered at $n^{\prime}=n-\left|i-i^{\prime}\right|$. For $y_{0}=\Delta$, the pulse will be centered at time step $n^{\prime}=$ $n-1$ when $i=i^{\prime}$. For $i \neq i^{\prime}$, the pulse will be active for a portion of two time steps, namely, $n^{\prime}=n-1-\left|i-i^{\prime}\right|$ and $n^{\prime}=n-\left|i-i^{\prime}\right|$. The problem is to determine the relative weighting between these time steps for $\mathrm{y}_{0} \leq \Delta$.

First, consider the case $y_{0} \cong \Delta$ which was discussed in the body of the paper. An approximation for (B1) is 


$$
\int_{\left(\left|i-i^{\prime}\right|-\frac{1}{2}\right) \Delta}^{\left(\left|i-j^{\prime}\right|+\frac{1}{2}\right) \Delta} d u \frac{P_{\Delta t}\left(\left(n-n^{\prime}\right) \Delta-\Delta \sqrt{ }\left[\left(y_{0} / \Delta\right)^{2}+\left|i-i^{\prime}\right|^{2}\right]\right)}{2 \pi \sqrt{ }\left[y_{0}{ }^{2}+u^{2}\right]}
$$

where the spatial variation in the time pulse has been taken to be the midpoint of the domain of integration. The square root reduces the active area for time step $n^{\prime}=n-$ $\left|1-1^{\prime}\right|$ by $\beta\left|1-1^{\prime}\right|=\sqrt{ }\left(y_{0} / \Delta\right)^{2}+\left|1-1^{\prime}\right|^{2}|-| 1-1^{\prime} \mid$, and therefore increases the area for $n^{\prime}=n-1-\left|i-l^{\prime}\right|$ by the same amount. This leads to the simple approximation for the retarded integral used in the body of the paper, and is valid for $y_{0} \cong \triangle$.

The general case $a<y_{0} \leq \Delta$ requires care. Each of the two active time steps will be considered separately, For the case $n^{\prime}=n-1-\left|1-i^{\prime}\right|$, the time pulse can be written in terms of the Heavyside function, $U(\xi)$, defined by $U(\xi)=1$ if $\xi>0$ and $\mathrm{U}(\xi)=0$ if $\xi \leq 0$, as

$$
\begin{aligned}
& P_{\Delta t}\left(\left(\left|i-i^{\prime}\right|+1\right) \Delta-\sqrt{ }\left[y_{0}^{\prime}{ }^{2}+u^{2}\right]\right)= \\
& U\left(\sqrt{ }\left[y_{0}{ }^{2}+u^{2}\right]-\left(\left|i-i^{\prime}\right|+1 / 2\right) \Delta\right)-U\left(\sqrt{ }\left[y_{0}{ }^{2}+u^{2}\right]-\left(\left|i-i^{\prime}\right|+3 / 2\right) \Delta\right) .
\end{aligned}
$$

Over the domain of integration in (B1), the range of the square-root function is

$$
\left.\sqrt{ }\left[y_{0}^{2}+\Delta^{2}\left(\left|i-j^{\prime}\right|-\frac{1}{2}\right)^{2}\right] \leq \sqrt{ }\left[y_{0}^{2}+u^{2}\right] \leq \sqrt{ } y_{0}^{2}+\Delta^{2}\left(\left|j-j^{\prime}\right|+\frac{1}{2}\right)^{2}\right\} ;
$$

thus, the second Heavyside function in (B2) is always zero for $y_{0} \leq \Delta$. Consequently, (B1) at $n^{\prime}=n-1-\left|i-i^{\prime}\right|$ is

$$
\int_{\left(\left|i-i^{\prime}\right|-\frac{1}{2}\right) \Delta}^{\left(\left|i-j^{\prime}\right|+\frac{1}{2}\right) \Delta} d u \frac{U\left(\sqrt{ }\left[y_{0}{ }^{2}+u^{2}\right]-\left[\left|i-i^{\prime}\right|+\frac{t}{2}\right] \Delta\right)}{2 \pi \sqrt{ }\left[y_{0}{ }^{2}+u^{2}\right]},
$$


and at $n^{\prime}=n-|1-|^{\prime} \mid$,

$$
\left.\int_{\left(\left|i-i^{\prime}\right|--\frac{1}{b}\right) \Delta}^{\left(\left|1-j^{\prime}\right|+\frac{1}{2}\right) \Delta} d u \frac{1}{2 \pi \sqrt{ }\left[y_{0}^{2}+u^{2}\right\}}\left\{1-U\left(\sqrt{ } y_{0}^{2}+u^{2}\right]-\left(|1-|^{\prime} \mid+\frac{1}{2}\right) \Delta\right)\right\} .
$$

By rewriting the Heavyside function as $U(\xi)=\operatorname{sign}(\xi) / 2+1 / 2$, the integrals can be evaluated to yeld the following results for (B1):

$$
\int_{\left(\left|i-i^{\prime}\right|-\frac{1}{2}\right) \Delta}^{\left(\left|i-i^{\prime}\right|+\frac{1}{2}\right) \Delta} \frac{\left.P \Delta t\left(\left(n-n^{\prime}\right) c \Delta t-\sqrt{ } \mid y_{0}{ }^{2}+u^{2}\right]\right)}{2 \pi \sqrt{ }\left[y_{0}{ }^{2}+u^{2}\right]}=
$$

$\underline{1 .} i=1$

$$
\begin{aligned}
& \text { (a) } n^{\prime}=n-1: \quad \tau_{0}^{n-1}=\left[\begin{array}{ll}
\frac{1}{\pi} \ln \left[\frac{\sqrt{1+\left(2 y_{0} / \Delta\right)^{2}}+1}{\sqrt{1-\left(2 y_{0} / \Delta\right)^{2}}+1}\right] & a<<y_{0} \leq \Delta / 2 \\
\frac{1}{2 \pi} \ln \left[\frac{\sqrt{1+\left(2 y_{0} / \Delta\right)^{2}}+1}{\sqrt{1+\left(2 y_{0} / \Delta\right)^{2}}+1}\right] & \Delta / 2 \leq y_{0} \leq \Delta
\end{array}\right. \\
& \text { (b) } n^{\prime}=n: \quad \tau_{0}^{n}=\left[\begin{array}{ll}
\frac{1}{\pi} \ln \left[\frac{\sqrt{\left.1-\left(2 y_{0} / \Delta\right)^{2}\right]+1}}{\left(2 y_{0} / \Delta\right)}\right] & a<y_{0} \leq \Delta / 2 \\
0 & \Delta / 2 \leq y_{0} \leq \Delta
\end{array}\right.
\end{aligned}
$$

\section{$\underline{I I, i \neq i^{\prime}}$}

(a.) $n^{\prime}=n-1-\left|1-i^{\prime}\right|$ :

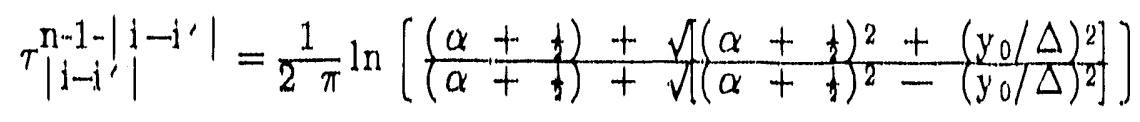

(b) $n^{\prime}=n-\left|i-i^{\prime}\right|$ :

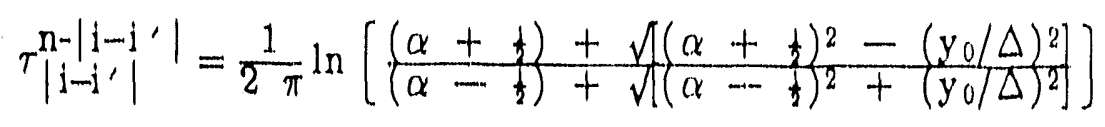


with $\alpha=\left|1-1^{\prime}\right|, 1 \neq 1^{\prime}$, and $a<<y_{0} \leq \Delta$.

These final expresulons represent the exact coefflctents for $\mathrm{K}_{1}^{\mathrm{n}-1-|1-|^{\prime} \mid}$ and $\mathrm{K}_{1}^{\mathrm{n}-||-\mathrm{I}^{\prime} \mid}$ and are valld for $\mathrm{a} \ll y_{0} \leq \Delta, c \Delta t=\Delta$. The integration over the magnetic current ds

$$
\begin{aligned}
& \left.\int_{-L / 2}^{L / 2} d x^{\prime} \frac{K_{x}\left(x^{\prime} ; t-R_{y_{0}} / c\right)}{2 \pi R_{y_{0}}}\right|_{\substack{x=1 \Delta \\
t=(n-t) \Delta t}} \cong \\
& \sum_{1^{\prime}=1}^{N}\left[\tau_{\mid 1-1}^{n-1-1}\left|1^{1-1^{\prime}}\right| K_{1}^{n-1-\left|1-1^{\prime}\right|}+\tau_{\left|1-1^{\prime}\right|}^{n-\left|1-1^{\prime}\right|} K_{1}^{n-\left|1-1^{\prime}\right|}\right] .
\end{aligned}
$$




\section{DISTIRIBU'ITON:}

Air Force Weapons Laboratory

Kirtland Air Force Base

Albuquerque, NM 87117-6008

Attn: $R$, J. Hamilton, AFWL/TALR (1)

D. A. Knght, AFWL/TALV (1)

T. Settecerri, AFWL/TAL (1)

W. Baker, AFWL/AWP (1)

P. Vaul, AFWL/TAL (1)

D. Hilland, AFWL/NTAT (1)

R. L, Schlicher, AFWL/AWPB (1)

T. Timmerman, AFWL/AWE (1)

Defense Nuclear Agency Headquarter,

6801 Telegraph Rd.

Alexandria, VA 22310-3398

Attn: Dr, G. Buker (1)

EMA

5101 Copper Av, NE, Suite 201

Albuquerque, NM 87108

Attn: Dr. D.E. Merewether (1)

General Dynamics-Pamona

$401-01$

P. O. Box 507

Pamona, CA 91760

Attn: R. McDonald (1)

K. Brown (1)

Harry Dlamond Laboratory

2800 Powder Mill Rd.

Adelphi, MD 20783-1107

Attn: L. F. Libelo (1)

A. Bromborsky (1)

J. Tatum (1)

E. Brown (1)

JAYCOR

11011 Torreyana Rd.

P. O. Box 85154

San Diego, CA 82121

Attn: E. P. Wenaas (1)

R. Leadon (1)

JAYCOR

39650 Liberty St.

Suite 320

Fremont, CA 94538

Attn: Dr. K. Casey (1) 

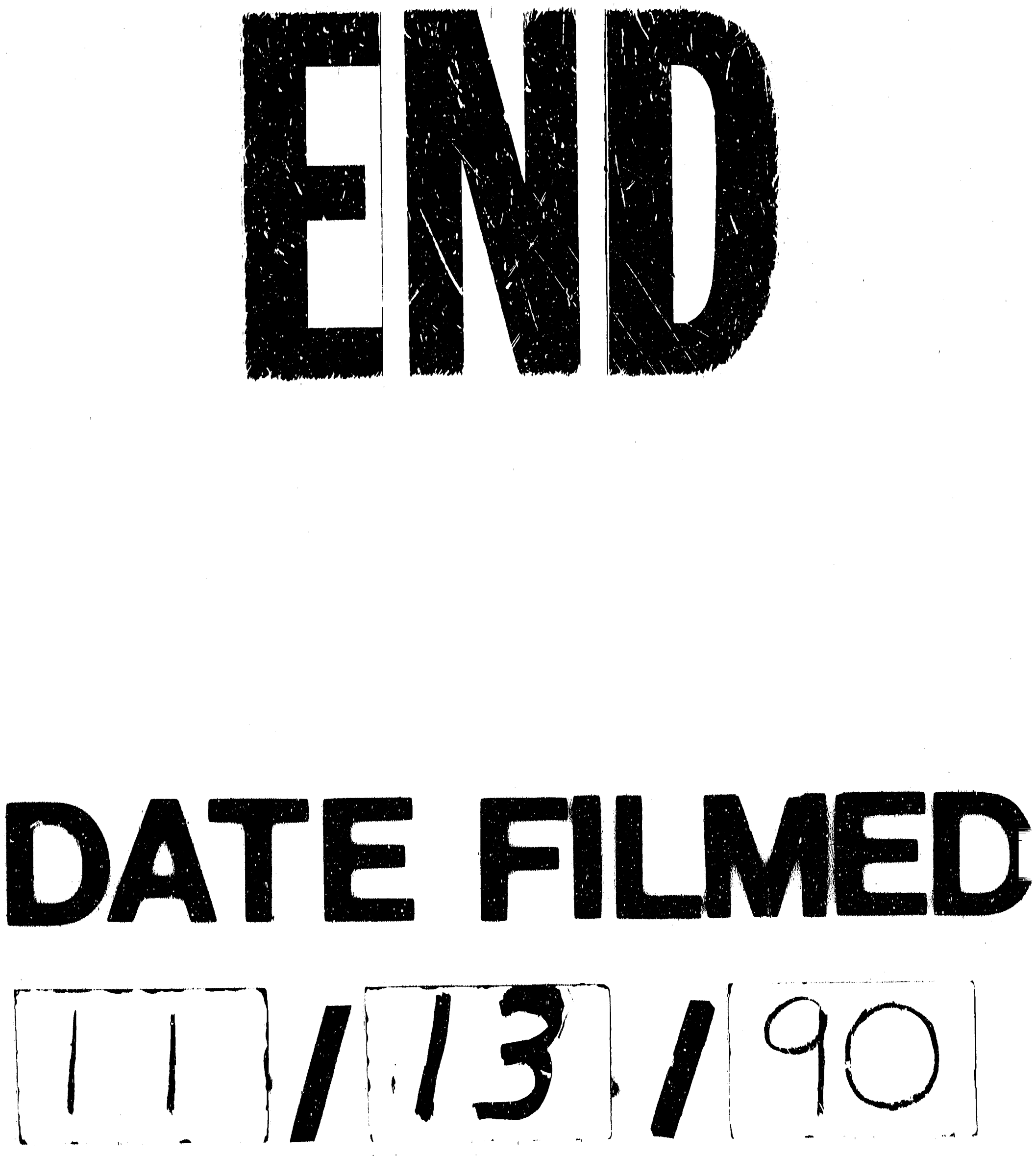
